\title{
NIIEH
}

\section{A TECHNICAL REPORT}

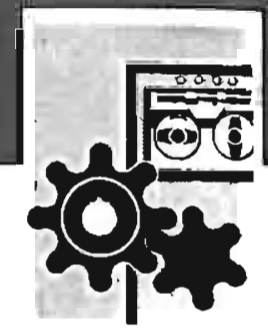

\section{USPHS/NIOSH MEMBRANE FILTER METHOD FOR EVALUATING AIRBORNE ASBESTOS FIBERS}

U. S. DEPARTMENT OF HEALTH, EDUCATION, AND WELFARE

Public Health Service

Center for Disease Control

National Institute for Occupational Safety and Health 
Mention of company name or product does not constitute endorsement by the National Institute for Occupational Safety and Health. 


\section{FOREWORD}

For over 50 years asbestos has been known to cause asbestosis, a nonmalignant scarring of the lungs. Recently asbestos has been associated with bronchogenic carcinoma, pleural mesothelioma, peritoneal mesothelioma, and cancer of the stomach, colon, and rectum.

In the United States an estimated 83,000 workers in the manufacture or installation of asbestoscontaining products are exposed full-time to asbestos dust. The activities of these workers is estimated to cause secondary exposures to approximately three to five million other building construction and shipyard workers.

One of the most important steps toward protecting workers from the risk of impaired health resulting from inhalation of asbestos fibers is the proper measurement and evaluation of employee exposure to asbestos. Exposure measurements must be unbiased statistically sound samples of employee exposure. To meet this need this manual was written to state NIOSH recommendations for measuring and evaluating employee exposures to asbestos fibers and to make this information available to those concerned with providing a safe and healthful place of employment.

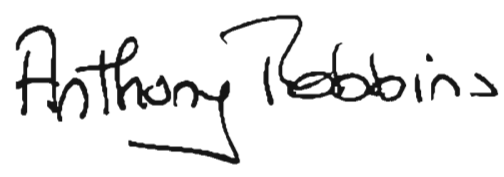

Anthony Robbins, M.D. Director, National Institute for Occupational Safety and Health 


\section{PREFACE}

It has been almost eleven years since the last detailed information was published by the National Institute for Occupational Safety and Health (NIOSH) concerning an asbestos counting method (Edwards and Lynch, 1968).

This report was prepared to expand on this previous paper. It incorporates much of the sampling and analytical experience of the last eleven years accumulated by counts made by NIOSH laboratories and the Occupational Safety and Health Administration (OSHA) Analytical Services Laboratory. The report attempts to answer many of the practical questions conceraing the method. A draft of this report has been used for the last four years by the NIOSH Division of Training in a course on asbestos sampling and analysis.

This NIOSH report contains the NIOSH technical guidelines, and procedures for the USPHS/NIOSH membrane filter method. The guidelines of this NIOSH report should be carefully and consistently followed by personnel collecting and evaluating asbestos samples in order to yield satisfactory results.

The method described herein was first used by the Asbestosis Research Council in Great Britain and later was modified by the U.S. Public Health Service (USPHS) for asbestos dust studies in the United States. It has been referenced as the method of test in the Occupational Safety and Heal th Administration (OSHA) Federal standard for asbestos in industrial air (29 CFR Part 1910.1001, formerly 29 CFR 1910.93a); in the Mine Safety and Health Administration (MSHA) regulations 30 CFR 55.5-1(b), 56.5-1(b), 57.5-1(b), and 71.202; and in the NIOSH Revised Criteria Document on Occupational Exposure to Asbestos. It is the method used by the National Institute for Occupational Safety and Health (NIOSH) and taught in the NIOSH Division of Training, Course 582, "Sampling and Evaluating Airborne Asbestos Dust." The procedure has been submitted to the American Society for Testing and Materials (ASTM) for consideration as an ASTM Method of Test.

In addition to keeping up with technical developments, those responsible for health and safety at the workplace must stay aware of the latest legal decisions regarding monitoring regulations for asbestos exposures. For example, the Occupational Safety and Health Review Commission (OSHRC) has ruled (OSHRC Docket \#13442, May 12, 1977) on the requirements in 29 CFR $1910.1001(f)(1)$ which create a duty for employee monitoring "where asbestos fibers are released."

The Review Commission stated: "Thus, to prove a violation, (the government) must establish that it is more likely than not that fibers were released... . We therefore reject the argument that (the government) need only show a 'genuine possibility' of release." 
The employer who is genuinely interested in the health protection of his employees may sometimes have to exceed minimum legal requirements in order to provide the best health protection for his employees. This is understandable when one considers the activity in occupational health and safety research and the time involved in translating research information into laws and regulations.

January 1979

Nelson A. Leidel

Rockville, Maryland

Stephen G. Bayer

Ralph D. Zumwalde

Kenneth A. Busch

Cincinnati, Ohio 


\begin{abstract}
This report describes the equipment and procedures for collecting, mounting, sizing, and counting asbestos fibers on cellulose ester membrane filters for the evaluation of personal samples of airborne asbestos fibers. Procedures for treating random and systematic errors are presented. These include statistical procedures for determining compliance with asbestos exposure standards. An evaluation of five phase contrast microscopes for asbestos counting is also given.

The purpose of the method presented is to determine an employee's exposure to airborne asbestos fibers as referenced in the Federal standard on occupational exposure to asbestos (29 CFR 1910.1001, formerly 29 CFR 1910.93a) and the Mine Safety and Health Administration (MSHA) air quality standards (30 CFR 55.5-1(b), 56.5-1(b), 57.5-I(b), and 71.202). The method is used by the National Institute for Occupational Safety and Health (NIOSH) and the occupational Safety and Health Administration (OSHA).
\end{abstract}




\section{CONTENTS}

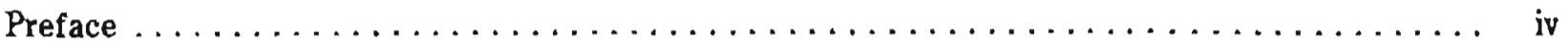

Abstract $\ldots \ldots \ldots \ldots \ldots \ldots \ldots \ldots \ldots \ldots \ldots \ldots \ldots \ldots \ldots \ldots \ldots \ldots \ldots$ vi

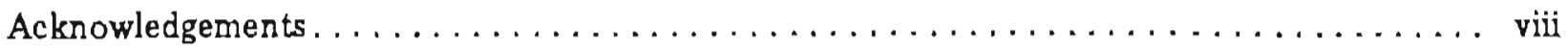

Introduction $\ldots \ldots \ldots \ldots \ldots \ldots \ldots \ldots \ldots \ldots \ldots \ldots \ldots \ldots \ldots \ldots \ldots \ldots \ldots$

History of the Asbestos Count Method As Used By NIOSH $\ldots \ldots \ldots \ldots \ldots \ldots \ldots \ldots \ldots \ldots$

Sources of Variation In the NIOSH Asbestos Monitoring Procedure . . . . . . . . . . . 3

Measures of An Analytical Method's Precision (Random Variations) . . . . . . . . . . . 3

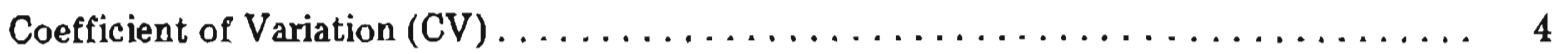

Observed Differences Between Two Simultaneous Measurements . . . . . . . . . . . . 4

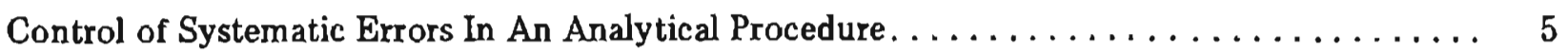

NIOSH Analysis of Johns-Manville Corporation Study Data . . . . . . . . . . . . . 7

Statistical Analysis of Asbestos Exposure Measurement Sample Results . . . . . . . . . . . . . 8

A Single Full-Period 8-Hour Sample . . . . . . . . . . . . . . . . . 9

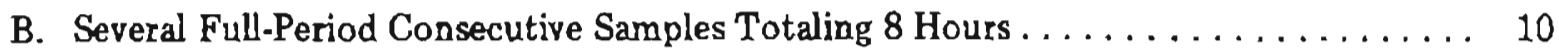

C. Several Partial-Period Consecutive Samples Totaling Less Than 8 Hours . . . . . . . . 13

D. Grab Samples (less than 30 samples) $\ldots \ldots \ldots \ldots \ldots \ldots \ldots \ldots \ldots \ldots$

References. .................................. 15

\section{FIGURES}

1. Variance-weighted linear regression of Johns-Manville $\log _{10}$-transformed data . . . . . 17

2. Regression line of Figure 1 plotted on Johns-Manville data in original units . . . . . . . . 18

3. Total coefficient of variation as a function of total fiber count. . . . . . . . . . . 19

Attachment: NIOSH Memorandum on "A Systematic Approach to the

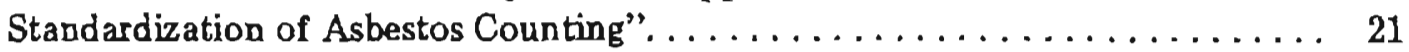

\section{APPENDICES}

A. NIOSH Analytical Method \# P\&CAM 239: Asbestos Fibers in Air. . . . . . . . . . . 23

B. An Evaluation of Phase Contrast Microscopes for Asbestos Counting (originally released as NIOSH Report TR-92, March 1974) . . . . . . . . . . . 57

C. Unbiased Estimates of Coefficients of Variation for Asbestos Counting Determined From Johns-Manville Data . . . . . . . . . . . . . . . . . . . 69

D. OSHA Asbestos Regulations 29 CFR $1910.1001 \ldots \ldots \ldots \ldots \ldots \ldots$ 


\section{ACKNOWLE DGE MENTS}

The authors gratefully acknowledge the suggestions and assistance of the following individuals: Philip J. Bierbaum, George A. Carson, R. Earle Conway, John M. Dement, Willard C. Dixon, Haxry Ettinger, Richard W. Hornung, Ge off Knight, William H. Krebs, Kay Dumler, Jeremiah R. Lynch; Robert Magor, Milton Sheinbaum, and David Taylor. Special thanks are due John F. Vining, III, for assembling the initial version of this report. Finally very special thanks are due Myra D. Brooks, Mary K. Geimeier, Pauline J. Elliott, and Evelyn A. Jones for typing the many versions of this report. 


\section{INTRODUCTION}

The OSHA proposed asbestos standard of 9 October 1975 would lower the 8-hour TWA permissible exposure limit (PEL) from the present value of 2 fibers $/ \mathrm{cm}^{3}$ to 0.5 fiber $/ \mathrm{cm}^{3}$. The proposed standard requires employers to conduct asbestos exposure monitoring of employees. Specifically, section (e) of the proposal states in part:

"The purpose of all monitoring required by this paragraph is to measure accurately the airborne concentrations of asbestos fibers in a workplace to which employees would be exposed if they worked in the area without the use of personal protective equipment such as respirators. Monitoring shall be performed in a manner reasonably calculated to satisfy this purpose."

Section $(e)(3)$ of the proposal requires:

"Method of measurement. All determinations of airborne concentrations of asbestos fibers shall be made by the membrane filter method at 400-450X (magnification) ( 4 millimeter objective) with phase contrast illumination."

Additionally, informative Appendix B - Substance Technical Guidelines, advises under section IV(B):

"The recommended sampling and evaluation method is described in the paper 'USPHS/NIOSH Membrane Filter Method for Evaluating Airborne Asbestos Fibers' by Nelson A. Leidel, Stephen G. Bayer, Ralph D.

Zumwalde, and Kenneth A. Busch. U.S. Department of Health, Education, and Welfare, Public Health Service, Center for Disease Control, National Institute for Occupational Safety and Health, Cincinnati, Ohio 45226."

This method is currently referenced as NIOSH Analytical Method 非\&CAM 239, Asbestos Fibers in Air, which is reprinted as Appendix A of this Report. 
In January 1964, the Division of Occupational Health (NIOSH's predecessor) of the U.S. Public Health Service commenced an epidemiological study of the asbestos products industry in the United States. Several different exposure measurement methods, including the membrane filter method, were used during the study which continued into the late 1960's. A discussion of the various methods was given by Lynch and Ayer (1) in 1966. The methods were later evaluated by Lynch et al. (2) in 1970.

The first published version of the membrane filter method as used by the USPHS/DOH was given by Edwards and Lynch (3) in 1968. In July 1972, Bayer and Zumwalde of NIOSH assembled a more detailed version (4) of the membrane filter count method based on material prepared for use in the NIOSH training course \#582, Sampling and Evaluating Airborne Asbestos Dust. This report was informally circulated to those requesting information on NIOSH guidelines for counting asbestos.

In 1973, Leidel, Bayer, and Zumwalde (5) prepared a more detailed version of the method for submittal to the American Society for Testing and Materials (ASTM) Committee D22.04. This 1973 report was used in NIOSH training courses and was referred to as in-house report $T R-84$ although it was never formally published by NIOSH. This report contained the first NIOSH estimate of the method's precision and accuracy, based on the literature available in 1973. The primary reference upon which the 1973 NIOSH precision estimate was based consisted of a study performed under a contract financed by the Asbestos Information Association/North America. Conway and Holland (6) reported the results of the study in February 1973.

During 1974 and 1975, draft versions of the NIOSH report received extensive review from members of the ASTM D22.04 Committee and members of the Joint AIHA-ACGIH Aerosol Hazards Evaluation Committee. In 1975 the Joint AIHA-ACGIH Committee independently published $(7,8)$ information on procedures for sampling and counting asbestos fibers. Their recommendations relied upon draft versions of the NIOSH procedure supplied to the committee. In late 1975, after the publication of the OSHA proposed asbestos standard, Leidel et al. of NIOSH revised once again the asbestos count method incorporating the technical comments received from the two committees mentioned previously and other reviewers.

In February 1976, Dr. Morton Corn, Assistant Secretary of Labor for OSHA requested Dr. Finklea, Director of NIOSH, to review the precision associated with the laboratory evaluation procedure for measuring asbestos in air. As part of the NIOSH response to OSHA's request, the NIOSH method's senior author extensively reviewed the literature, especially articles appearing in 1974 and 1975, and prepared a revised four-page review of the method's precision and accuracy. At the same time the format of the method was made consistent with that of other NIOSH Physical and Chemical Analysis Branch 
(now designated the Measurements Research Branch) analytical methods. After extensive literature review, in 1976, the NIOSH authors concluded that the Conway and Holland (6) results still represented the most carefully controlled study and best estimate of the method's precision. The NIOSH authors felt that the stated precision of $\mathrm{CV}=0.22$ was reasonable and attainable for laboratories with properly calibrated and adjusted equipment, where counters are properly trained and their counting efficiency is continually evaluated.

\section{SOURCES OF VARIATION IN THE NIOSH ASBESTOS MONITORING PROCEDURE}

In the NIOSH asbestos count method (Appendix A) a review is given of the major sources of variation in the procedure. The following table summarizes the sources of variation in procedure. The important difference between random variations and systematic biases is discussed in the next two sections.

\section{Variation Source}

1. Intrafilter (consisting of interfield within a wedge and interwedge within a filter)

2. Intercounter

3. Interfilter (within simultaneous samples)

4. Interlaboratory

5. Environmental

\section{Possible Causes and Nature}

The counting procedure only "samples" and estimates the filter surface fiber density. Random variations with some likelihood of small systematic biases between wedges that can be treated as random.

Some random variations exist, but differences are primarily systematic due to improper training, lack of experience, attitude, poor visual acuity, or no quality control programs.

Random variations due to random fluctuations in pump flow rate. Systematic biases due to improper pump calibration.

Systematic variations due to differences in microscope quality and specifications, improper microscope adjustment, counter training, or improper application of the method.

Both random variations and systematic biases due to concentration changes in time and space.

\section{MEASURES OF AN ANALYTICAL METHOD'S PRECISION (RANDOM VARIATIONS)}

Literature articles often discuss precision in terms of the coefficient of variation ( $\mathrm{CV}$ ) as well as in terms of ranges of observed differences between 
reported values. These two concepts are related, but are statistically different and cannot be directly compared. The following is a discussion of the statistical relation between the two concepts.

\section{Cofficient of Variation (CV)}

The relative variation or dispersion of a normal distribution (such as the random variations in a sampling and analytical procedure) is commonly measured by the coefficient of variation. The CV is al so known as the relative standard deviation. It is calculated by dividing the standard deviation of the data by the arithmetic average of the data. The $\mathrm{CV}$ is a useful parameter of dispersion in that limits consisting of the true mean of a data set, plus or minus twice the standard deviation, will contain about $95 \%$ of the data measurements. This is a rough approximation, that depends on the number of data values from which the mean and standard deviation were calculated. If an analytical procedure with a known $C V$ of 0.10 were used to repeatedly measure some fixed physical property (such as the concentration of a chemical in a beaker of solution measured about 30 or 40 times), then about $95 \%$ of the measurements would fall within plus or minus $20 \%$ (twice the $\mathrm{CV}$ ) of the true concentration, assuming an unbiased procedure.

\section{Observed Differences Between Two Simultane ous Measurements}

When simultaneous "paired" measurements are performed on a series of physical objects, such as "paired" counts by two technicians on a series of asbestos filters, differences are observed between the two counts reported by the two counters of each filter. If the absolute value of each difference is obtained, we can discuss the Distribution of Absolute Differences, which has several statistical properties. First, the distribution is the right half of a normal "bell-shaped" distribution, truncated on the left at zero and with a tail to the right. Second, the mean of the distribution occurs at 1. $128\left(s_{m}\right)$, where $\left(s_{m}\right)$ is the standard deviation of the analytical method. This particular mean can also be estimated from $1.128(\mathrm{CV})(\bar{x})$, where $(\bar{x})$ is the mean of the original measurements. Third, it is important to realize that seemingly large differences between paired measurements (or two asbestos counters) can occur due to chance alone. The following table shows the per cent of absolute difference that can exceed the indicated value due to the chance alone:

$$
\begin{aligned}
& 20 \% \text { can exceed } 1.81\left(\mathrm{~s}_{\mathrm{m}}\right) \text { due to chance alone } \\
& 10 \% \text { can exceed } 2.33\left(\mathrm{~s}_{\mathrm{m}}\right) \text { due to chance alone } \\
& 5 \% \text { can exceed } 2.77\left(\mathrm{~s}_{\mathrm{m}}\right) \text { due to chance alone }
\end{aligned}
$$

For example, suppose a series of filters is exposed to an asbestos contaminated atmosphere with an average concentration of $1.0 \mathrm{f} / \mathrm{cc}$. For a total fiber count of 100 fibers, the $\mathrm{CV}_{\mathrm{T}}$ for the NIOSH method is 0.115 . Then at $1.0 \mathrm{f} / \mathrm{cc}$ the 
method has $s_{m}=0.115 \mathrm{f} / \mathrm{cc}$. For a series of paired counts at this level we could expect the following to happen regarding the observed differences between pairs of counts:

a) $20 \%$ of the pair differences could exceed $0.2^{1} \mathrm{f} / \mathrm{cc}$ due to chance alone ( $s u c h$ as $0.9 \mathrm{f} / \mathrm{cc}$ and $1.11 \mathrm{f} / \mathrm{cc}$ )

b) $10 \%$ of the pair differences could exceed $0.27 \mathrm{f} / \mathrm{cc}$ due to chance alone (such as $0.85 \mathrm{f} / \mathrm{cc}$ and $1.12 \mathrm{f} / \mathrm{cc}$ )

c) $5 \%$ of the pair differences could exceed $0.32 \mathrm{f} / \mathrm{cc}$ due to chance alone ( $s u c h$ as $0.84 \mathrm{f} / \mathrm{cc}$ and $1.16 \mathrm{f} / \mathrm{cc}$ )

Large differences between counters of the same filter (or between counts of two filters taken at exactly the same location and time) are not indicative of poor precision for an analytical method. Observed and reported differences (especially "maximum" ones from small numbers of observations must be examined in light of the preceding statistical relationships. Some authors report "percent differences." This term is meaningless unless the divisor count is given. Suppose we have two counts of $0.8 \mathrm{f} / \mathrm{cc}$ and $1.46 \mathrm{f} / \mathrm{cc}$. Using $0.8 \mathrm{f} / \mathrm{cc}$ as a denominator, one might see reported a "83\% difference in counts."

\section{CONTROL OF SYSTEMATIC ERRORS IN AN ANALYTICAL PROCEDURE}

Large differences in asbestos fiber counts are often observed in collaborative programs $(9,10)$. It is worthwhile to review the 1960 comments of the eminent analytical chemist and statistician, W. J. Youden (11):

"Thoughtful consideration of the steps in an analytical procedure soon leads to the conclusion that differences between laboratories in regard to equipment, reagents, or in procedures are more likely to lead to systematic errors than to changes in precision."

"Finally there is an abundance of evidence that different laboratories have different systematic errors for a given procedure."

". . it seems fair to conclude that laboratories with equivalent equipment and personnel achieve about the same precision."

"In any event the evidence is conclusive that differences in the systematic errors are the major source of disagreement among laboratories."

In 1963 Youden stated (12):

"If the between-laboratory error is several times as large as the precision established by the originating laboratory, some of the laboratories are probably unintentionally deviating from the routine followed in the originating laboratory." 
The British use a membrane filter method for sampling airborne asbestos which is very similar to the NIOSH method. Their experience has also shown the difficulties in trying to obtain closely comparable results between counters in different laboratories. Beckett and Attfield (9) have reported the results of two studies aimed at examining the problem. The first study examined the variation in asbestos counts between inexperienced laboratories learning to count asbestos on the basis of published descriptions. The second study looked at the level of agreement between experienced units regularly engaged in counting asbestos slides. Beckett and Attfield (9) concluded that:

"In the trial between inexperienced laboratories, novice counters using only the published instructions obtained results which were of the order of half those of the standard laboratories for industrial samples and a quarter for UICC chrysotile asbestos. Following personal instruction, however, good agreement was obtained between all laboratories for industrial slides, and a greatly improved agreement (67 per cent) for UICC chrysotile."

"Exchanges of sample slides and personal tuition clearly improves the consistency of counters, experienced as well as inexperienced."

A NIOSH memorandum of October 4, 1972 entitled, "A Systematic Approach to the Standardization of Asbestos Counting" (attached) details specific proposals for reducing and controlling systematic errors between laboratories and counters analyzing asbestos samples. Unfortunately, NIOSH has not had the resources to implement all the proposals recommended by J. R. Lynch, although, NIOSH does offer Training Course \#582 at a cost of $\$ 200$ for three days training. Additionally, through its Proficiency Analytical Testing (PAT) Program, NIOSH provides standard asbestos samples on request to over 200 laboratories. NIOSH then reports to each laboratory the count results from that laboratory in comparison to the consensus average. However, NIOSH does not have any control over any corrective action that laboratories should take regarding their counters or procedures.

It is the NIOSH position that the $\mathrm{CV}_{\mathrm{T}}$ for the asbestos count method should measure the total (net) variation due to the following sources only: random intrafilter variations (interfield within a wedge and interwedge within a filter), random intercounter variations, and random pump flow rate variations. Random environmental fluctuations due to concentration variations in time and space obviously should not be considered in the $\mathrm{CV}_{\mathrm{T}}$. Random environmental variations within a particular sampling day are eliminated from sampling error by appropriate full-period sampling strategies as discussed in (13) and (14). Systematic errors in the asbestos count method and other analytical procedures are controllable and can be reduced by proper training and the diligent application of quality control procedures. Systematic variations and biases should not be included in the $C V_{T}$ of a method. 
In December 1975, the Johns-Manville Corporation initiated an in-house interlaboratory study of the NIOSH asbestos count method (15). The Johns-Manville study data (15) contained total fiber counts for over 100 filters, with each filter counted by two to five counters located in five laboratories. Each counter prepared their own wedge or slide for counting. From the data in, (15) NIOSH calculated over 100 estimates of the count CV for the asbestos method. Each count $\mathrm{CV}$ estimate involved one to four statisticé degrees of freedom. The very low degrees of freedom involved in the CV estimates is probably the most important reason for the observed dispersion in the CV estimates. This is to be expected since the sampling error of a variance is a common topic in basic statistics texts. The NIOSH calculated count $\mathrm{CV}$ estimates included random intrafilter variations and intercounter variations. The CV's did not include random pump flow rate variations. These were included later in the analysis.

Busch et al. (16) examined the count coefficient of variation (all but the random pump variations) as a function of the total fibers counted on a particular wedge (total fiber count). Their report is reprinted as Appendix C in this report. Logarithms (base 10) were taken of the transformed count coefficient of variation and total fiber count and the transformed variables are shown in Figure 1 of Appendix C. Then a variance-weighted linear regression was performed on the transformed variables. The line plotted on Figure 1 of Appendix $C$ is the best estimate of $\log _{10}$ (true coefficient of variation) for total fiber counts in the range 10 to 100 . The same CV-estimator is plotted on Figure 2 of Appendix C which shows the NIOSH calculated CV estimates in original units. NIOSH then included a CV of 0.05 for random pump variations in the CV-estimator equation to calculate a $\mathrm{CV}_{\mathrm{T}}$-estimator for the total coefficient of variation of the asbestos count method. The $\mathrm{CV}_{\mathrm{T}}$-estimator line is plotted on Figure 3 of Appendix $\mathrm{C}$ against grid lines for ease of estimation of $\mathrm{CV}_{\mathrm{T}}$ at any particular total fiber count in the range 10 to 100 fibers.

Based on the Johns-Manville study data (15), Figure 3 of Appendix C demonstrates that for a total fiber count of 100 , the best $C V_{T}$ estimate is about 0.115 , while for a total fiber count of 10 the best $C V_{T}$ estimate is 0.41 . Thus, NIOSH states that the method has an attainable $C V_{T}$ of 0.115 based on the appropriate sampling times given in section 8.1.3 of Appendix A and the count rules in section 8.3.9 of Appendix A. Most importantly, Figure 3 of Appendix $C$ clearly shows that if the method is properly applied, typical $\mathrm{CV}_{\mathrm{T}}$ 's of 0.11 to 0.15 can be attained.

Although several CV estimates were in the 0.7 to 0.9 range, they had large standard errors because of their small sample sizes (usually only 2). None of the se large CV estimates differed significantly (at the $5 \%$ probability level) from the values given by the fitted line; therefore, none were excluded. That is, all the data were used to fit the line of Figure 1 of Appendix $C$ by the method of variance-weighted least squares. 
Once the random variations of an analytical procedure have been quantitatively estimated in terms of a $C V_{T}$, they can be allowed for in the decision making process with the generic NIOSH procedures of Leidel and Busch $(13,14)$. The following section will present specific statistical procedures based on those in (13) and (14), for the determination of compliance and noncompliance with the OSHA proposed asbestos standard of $0.5 \mathrm{f} / \mathrm{cc}$. These references should be consulted for additional statistical theory and its underlying assumptions.

\section{STATISTICAL ANALYSIS OF ASBESTOS EXPOSURE MEASUREMENT} SAMPLE RESULTS

For over six years NIOSH has conducted statistical research on the types of variations affecting NIOSH and OSHA exposure monitoring methods. Leidel and Busch (13) have developed statistical procedures that take account of these random variations. The procedures allow the calculation of confidence limits for the true airborne concentration of a contaminant. In 1975, Leidel and Busch (13) published NIOSH recommended statistical procedures for the collection and evaluation of sample results to determine if a state of noncompliance with an occupational health standard exists. With the se procedures the sample results of an occupational exposure may be compared and evaluated to an occupational health standard. Leidel and Busch (13) gave the following caveat regarding the statistical procedures:

"The statistical procedures presented below will not detect and do not allow for analysis of highly inaccurate results, i.e., systematic (nonrandom) errors or mistakes. The detection and elimination of mistakes is primarily a technical rather than a statistical problem. To assure accurate results one must have an instrument calibration program and a quality control program for laboratory analysis. Systematic errors must also be known ahead of time whether from the instrument calibration procedure or the laboratory quality control program."

Using the NIOSH recommended statistical procedures, both OSHA and employers can adequately and confidently monitor and determine compliance with the OSHA proposed asbestos standard of 0.5 fiber $/ \mathrm{cm}^{3}$ and the NIOSH recommended level of 0.1 fiber $/ \mathrm{cm}^{3}(17)$. 
Classification of exposure for the OSHA proposed 8-hour TWA standard (STD) of $0.5 \mathrm{f} / \mathrm{cc}$

A. Single Full-Period 8-hour Sample

\section{PROCEDURE}

1. Obtain the $A C$ and $C V . A C$ is the estimate of the airborne fiber concentration $(f / c c)$ calculated from the total fiber count (FB) (see sections 9.1.10 and 10.1 of Appendix A. The CV is a function of total fibers counted ( $F B$ ) and is read from Figure 3 of Appendix $C$.

Or this relation can be used:

$C V_{T}=\sqrt{\left\{\operatorname{sintlog}_{10}\left[0.0595-0.3241(\log F B)-0.01585\left(\log ^{2} F B\right)\right]-0.12\right\}^{2}+0.0025}$

2. Calculate the LCL or UCL:

a. Compliance officer's test for noncompliance.

$$
\operatorname{LCL}(95 \%)=A C-1.645(\mathrm{CV})(\mathrm{STD})
$$

b. Employer's test for compliance.

$$
\operatorname{UCL}(95 \%)=A C+1.645(\mathrm{CV})(\mathrm{STD})
$$

3. Classify the exposure average for the one sample:

a. Compliance officer's test for noncompliance.

if LCL > STD, state Noncompliance Exposure if $\mathrm{AC}>\mathrm{STD}$ and $\mathrm{LCL} \leqslant \mathrm{STD}$, state Possible Overexposure if $A C<S T D$, no statistical test for noncompliance would be made

b. Employer's test for compliance.

if UCL $\leqslant$ STD, state Compliance Exposure if UCL > STD, state Possible Overexposure

\section{EXAMPLE}

1. An airborne asbestos fiber level of about $0.5 \mathrm{f} / \mathrm{cc}$ was suspected. A microscope with a count field area of $0.003 \mathrm{~mm}^{2}$ and pump calibrated for $1.7 \mathrm{lpm}$ was available. The background particulate levels were considered light. From Figure 1 in the Appendix A it was determined that a sample time of 8 hours (480 minutes) would 
yield filter surface fiber densities in the optimum zone of about 1 fiber/field. When a filter wedge was counted, the total fibers counted in 100 fields was $95(=F B)$. No fibers were found on the blank filters. Figure 3 in Appendix $A$ showed a $C V_{T}$ of 0.12 for 95 fibers.

$$
A C=\frac{(95 / 100)(855)}{(1000)(1.7)(480)(.003)}=0.33 \mathrm{f} / \mathrm{cc}=8 \text {-hour TWA }
$$

2. a) LCL $=0.33 \mathrm{f} / \mathrm{cc}-1.645(.12)(.5 \mathrm{f} / \mathrm{cc})=0.23 \mathrm{f} / \mathrm{cc}$

note: In this case one would not compute an LCL since AC is already below the $0.5 \mathrm{f} / \mathrm{cc}$ STD.

b) UCL $=0.33 \mathrm{f} / \mathrm{cc}+1.645(.12)(.5 \mathrm{f} / \mathrm{cc})=0.43 \mathrm{f} / \mathrm{cc}$

3. a) Since $A C=0.33 \mathrm{f} / \mathrm{cc}$ is less than the $0.5 \mathrm{f} / \mathrm{cc}$ STD, the compliance officer would not need to make a statistical test for noncompliance.

b) Since the UCL of $0.43 \mathrm{f} / \mathrm{cc}$ is less than $0.5 \mathrm{f} / \mathrm{cc}$, the employer can state that the exposure was a Compliance Exposure.

B. Several Full-Period Consecutive Samples Totaling 8 Hours

\section{PROCEDURE}

1. Obtain $A C_{1}, \cdots, A C_{n}$ (the $n$ consecutive airborne fiber concentration measurements in $\mathrm{f} / \mathrm{cc}$ ). Obtain $\mathrm{CV}_{1}, \mathrm{CV}_{2}, \cdots, \mathrm{CV}_{\mathrm{n}}$ from Figure 3 of the NIOSH method for each of the $F_{1}, F B_{2}, \cdots, F B_{n}$ total fiber counts. Also record the durations for all samples $T_{1}, T_{2}, \cdots, T_{n}$.

2. Calculate the time-weighted average (TWA) exposure.

$$
T W A=\frac{T_{1} A C_{1}+T_{2} A C_{2}+\cdots T_{n} A C_{n}}{T_{1}+T_{2}+\cdots T_{n}}
$$

3. Calculate linear contributions to the TWA variance for each sample:

$$
v_{i}=\left[\frac{\left(T_{i}\right)\left(A C_{i}\right)\left(C V_{i}\right)}{\sum\left(T_{i}\right)}\right]^{2}
$$


4. Calculate the variance of the TWA by adding the linear contributions $\left(v_{i}\right)$.

$$
\operatorname{var}_{\text {TWA }}=v_{1}+v_{2}+\cdots v_{n}
$$

5. Calculate the standard error of the TWA

$$
\mathrm{SE}_{\mathrm{TWA}}=\sqrt{\mathrm{Var}_{\mathrm{TWA}}}
$$

6. Calculate the LCL or UCL.

a) Compliance officer's test for noncompliance.

$$
\operatorname{LCL}(95 \%)=\operatorname{TWA}-1.645\left(\mathrm{SE}_{\mathrm{TWA}}\right)
$$

b) Employer's test for compliance.

$$
\operatorname{UCL}(95 \%)=\mathrm{TWA}+1.645\left(\mathrm{SE}_{\mathrm{TWA}}\right)
$$

7. Classify the TWA exposure for the (n) samples.

'a) Compliance officer's test for noncompliance.

if LCL > STD, state Noncompliance Exposure

if TWA $>$ STD and LCL $\leqslant$ STD, state Possible Overexposure

if TWA $<$ STD, no statistical test for noncompliance is necessary

b) Employer's test for compliance.

if UCL $\leqslant$ STD, state Compliance Exposure if UCL > STD, state Possible Overexposure 


\section{EXAMPLE}

1. An airborne asbestos level of about $0.5 \mathrm{f} / \mathrm{cc}$ was suspected. A microscope with a count field area of $0.006 \mathrm{~mm}^{2}$ and pump calibrated for $1.7 \mathrm{lpm}$ was available. The background particulate levels were considered medium to heavy and from Figure 2 of Appendix $A$ it was determined that four consecutive samples of 120 minutes each would yield filter surface fiber densities of about 0.6 fiber/field. No fibers were counted on the blank filters. The results for 100 fields counted on each sample were:

\begin{tabular}{|c|c|c|c|}
\hline $\begin{array}{l}\text { Duration }\left(\mathrm{T}_{\mathrm{i}}\right) \\
\text { (minutes) }\end{array}$ & $\begin{array}{l}\text { Total fiber } \\
\text { count }\left(F B_{i}\right)\end{array}$ & $A C_{i}(f / c c)$ & $\mathrm{CV}_{\mathrm{i}}$ \\
\hline 100 & 65 & 0.55 & 0.15 \\
\hline 140 & 75 & 0.45 & 0.14 \\
\hline 110 & 55 & 0.42 & 0.17 \\
\hline 130 & 70 & 0.45 & 0.145 \\
\hline
\end{tabular}

2. $\mathrm{TWA}=\frac{(100)\langle 0.55)+(140)(0.45)+(110)(0.42)+(130)(0.45)}{100+140+110+130}$ $T W A=0.46 \mathrm{f} / \mathrm{cc}$

3.

\begin{tabular}{cccc}
$T_{i}$ & $\frac{T_{i} A C_{i} C V_{i}}{\sum T_{i}}$ & $v_{i}$ \\
\hline 100 & 0.0172 & & 0.000295 \\
140 & 0.0184 & 0.000338 \\
110 & 0.0164 & & 0.000268 \\
130 & 0.0178 & & 0.000312
\end{tabular}

$\begin{aligned} \sum \mathrm{T}_{\mathrm{i}} & =480 \\ \text { 4. } \operatorname{var}_{\mathrm{TWA}} & =0.000295+0.000338+0.000268+0.000312=0.001213\end{aligned}$

5. $\mathrm{SE}_{\mathrm{TWA}}=\sqrt{0.001213}=0.035 \mathrm{f} / \mathrm{cc}$

6. a) LCL not needed since TWA of $0.46 \mathrm{f} / \mathrm{cc}$ is less than $0.5 \mathrm{f} / \mathrm{cc}$.

b) $\mathrm{UCL}=0.46 \mathrm{f} / \mathrm{cc}+1.645(0.035 \mathrm{f} / \mathrm{cc})$ $=0.52 \mathrm{f} / \mathrm{cc}$

7. a) LCL not needed since $0.46 \mathrm{f} / \mathrm{cc}$ is less than $0.5 \mathrm{f} / \mathrm{cc}$.

b) Since $0.52 \mathrm{f} / \mathrm{cc}$ exceeds $0.5 \mathrm{f} / \mathrm{cc}$, the employer should state a Possible Overexposure. 
C. Several Partial-Period Consecutive Samples Iotaling Less Than 8-Hours

The employer computes the UCL for the average exposure level during the sampled portion of the day the same as in the previous section.

He then compares his UCL to the 8-hour standard which can only be accomplished if he assumes the same exposure during the unsampled portion of the workshift as existed during the measured portion. However the compliance officer should conservatively assume zero exposure for the unsampled portion of the workshift. See section 3.4 of Leidel et al. (13) for a discussion of this. The procedures of this section (C) are for the compliance officer only.

\section{PROCEDURE AND EXAMPLE}

Follow the procedure and example of sections $B(1)$ through $B(6)(2)$ above. Then calculate a partial period limit (PPL):

$$
\text { PPL }=(\text { TWA STD })\left[\frac{\text { period of TWA STD }(=8 \text { hours })}{\text { total time of samples }}\right]
$$

Suppose the four samples in the section $B$ example above had covered only 6.4 hours.

$$
P P L=(0.5 \mathrm{f} / \mathrm{cc})(8) /(6.4)=0.625 \mathrm{f} / \mathrm{cc}
$$

Classify the TWA exposure for the (n) samples with a test for noncompliance.

if LCL > PPL, state Noncompliance Exposure

if TWA > PPL and LCL $\leqslant$ PPL, state Possible Overexposure

if TWA < PPL, no statistical test for noncompliance would be used

Since $0.46 \mathrm{f} / \mathrm{cc}$ is less than $0.625 \mathrm{f} / \mathrm{cc}$, a test for noncompliance is not necessary.

\section{Grab Samples (less than 30 samples)}

If several short (about 5 to 30 minutes each) samples are taken to evaluate asbestos exposures, the grab samples decision procedures of section 4.2.3 of Leidel et al. (14) should be followed.

The statistical procedures given above clearly show that the NIOSH asbestos count method has the ability to evaluate compliance with either a $0.5 \mathrm{f} / \mathrm{cc}$ standard or a $2.0 \mathrm{f} / \mathrm{cc}$ standard. By rearranging the equations given above, we can compute critical values that measurements 
must exceed in order to demonstrate noncompliance at the NIOSH recommended $95 \%$ statistical confidence level. To demonstrate noncompliance, a single 8 -hour sample should exceed:

$$
\mathrm{STD}+1.645(\mathrm{CV})(\mathrm{STD})
$$

To demonstrate noncompliance, the time-weighted average (TWA) of several consecutive samples covering 8 hours should exceed:

$$
\mathrm{STD}+1.645\left(\mathrm{SE}_{\mathrm{TWA}}\right)
$$

Replace the plus signs with minus signs to compute the critical values measurements must lie below to demonstrate compliance. Measurements which are between the two critical values are in a statistical uncertainty zone that includes the standard. That is, the measurement results are not far enough from the standard to justify stating compliance or noncompliance at the $95 \%$ confidence level. For the OSHA proposed standard of $0.5 \mathrm{f} / \mathrm{cc}$, this zone is bounded by $0.4 \mathrm{f} / \mathrm{cc}$ and $0.6 \mathrm{f} / \mathrm{cc}$. Any single 8 -hour. sample that had a fiber count of about 100 and exceeded $0.6 \mathrm{f} / \mathrm{cc}$ could be declared a noncompliance exposure at the $95 \%$ statistical confidence level. There is a maximum $5 \%$ probability that the true exposure is less than $0.5 \mathrm{f} / \mathrm{cc}$ if the single measurement exceeds $0.6 \mathrm{f} / \mathrm{cc}$. If several consecutive samples were taken during the workshift, then the critical value would be generally lower than $0.6 \mathrm{f} / \mathrm{cc}$. 
1. Lynch, J. R. and H. E. Ayer: Measurement of Dust Exposures in the Asbestos Textile Industry, AIHAJ, 27, 431-437 (1966).

2. Lynch, J. R. Ayer, H. E. and D. L. Johnson: The Interrelationships of Selected Asbestos Exposure Indices. AIHAJ, 31, 598-604 (1970).

3. Edwards, G. H. and J. R. Lynch: The Method Used by the U.S. Public Health Service for Enumeration of Asbestos Dust on Membrane Filters, Ann. Occup. Hyg. , 11, 1-6 (1968).

4. Bayer, S. G. and R. D. Zumwalde: Evaluating Airborne Asbestos Dust, NIOSH unpublished in-house report (July 1972).

5. Leidel, N. A., Bayer, S. G., and R. D. Zumwalde: USPHS/NIOSH Membrane Filter Method for Evaluating Airborne Asbestos Fibers. NIOSH unpublished in-house report TR-84 (November 1973).

6. Conway, R. E. and W. D. Holland: Statistical Evaluation of the Procedure for Counting Asbestos Fibers on Membrane Filters, LFE Corporation, Richmond, CA, prepared for Asbestos Information Association/North America, New York, New York (February 1973).

7. Joint-ACGIH Aerosol Hazards Evaluation Committee: Recommended Procedures for Sampling and Counting Asbestos Fibers, AIHAJ, 36, 83-90 (1975).

8. Joint AIHA-ACGIH Aerosol Hazards Evaluation Committee: Background Documentation on Evaluation of Occupational Exposure to Airborne Asbestos, AIHAJ, 36, 91-103 (1975).

9. Beckett, S. T. and M. D. Attfield: Inter-Laboratory Comparisons of the Counting of Asbestos Fibres Sampled on Membrane Filters, Ann. Occup. Hyg., 17, 85-96 (1974).

10. Ortiz, L. W., Ettinger, H. J. and C. I. Eairchild: Calibration Standards for Counting Asbestos, AIHAJ, 36, 104-11.2 (1975).

11. Youden, W. J.: The Sample, The Procedure, and The Laboratory, Anal. Chem., 32, 23A-37A (1960).

12. Youden, W. J.: Ranking Laboratories by Round-Robin Tests, Nat. Res. and Stds., $\underline{3}, 9-13(1963)$. 
13. Leidel, N. A. and K. A. Busch: Statistical Methods for the Determination of Noncompliance with Occupational Health Standards, NIOSH Technical Information Report \#75-159 (April 1975).

14. Leidel, N. A., Busch, K. A., and J. R. Lynch: Occupational Exposure Sampling Strategy Manual, NIOSH Technical Information Report \#77-173 (January 1977).

15. Comments of the Johns-Manville Corporation with Respect to the Notice of Proposed Ruelmaking: Occupational Exposure to Asbestos, Federal Register, October 9, 1975. Submitted to the Public Record at the U.S. Department of Labor, Occupational Safety and Health Administration, Washington, D. C. , April 1976.

16. Busch, K. A., Leidel, N. A., Hornung, R. W. , and R. J. Smith: Unbiased Estimates of Coefficients of Variation for Data, presented to the Society for Occupational Environmental Health Conference in Washington, D.C. (December 1977). (Appendix C of this redort).

17. Revised Recommended Asbestos Standard, NIOSH Publication \#77-169 (December 1976). 


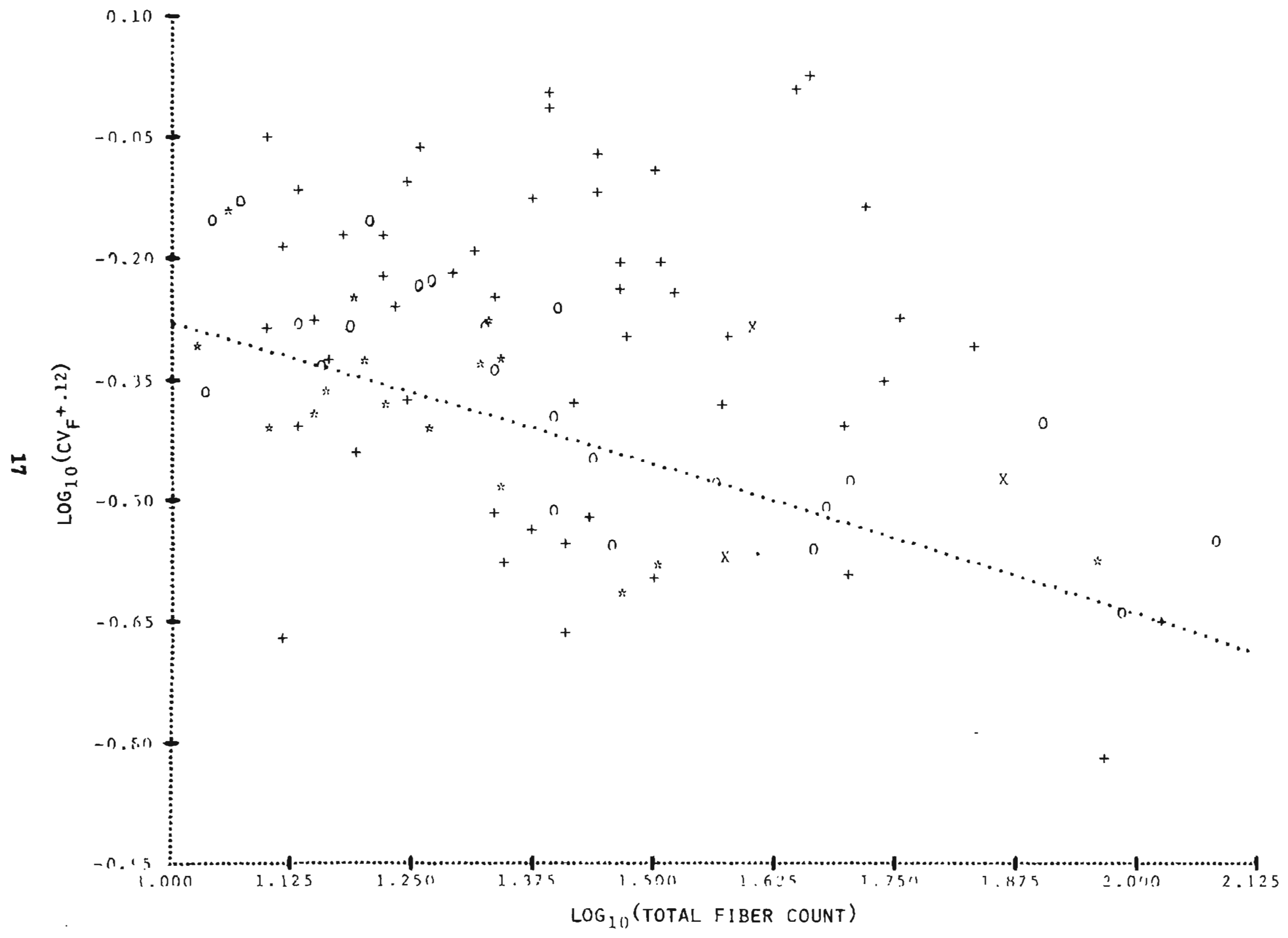

Figure 1 - Variance-weighted regression curve for $\log _{10}$-transformed Johns-Manville data (adjusted for bias and without pump error) 


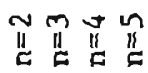

......

$+x 0 *$

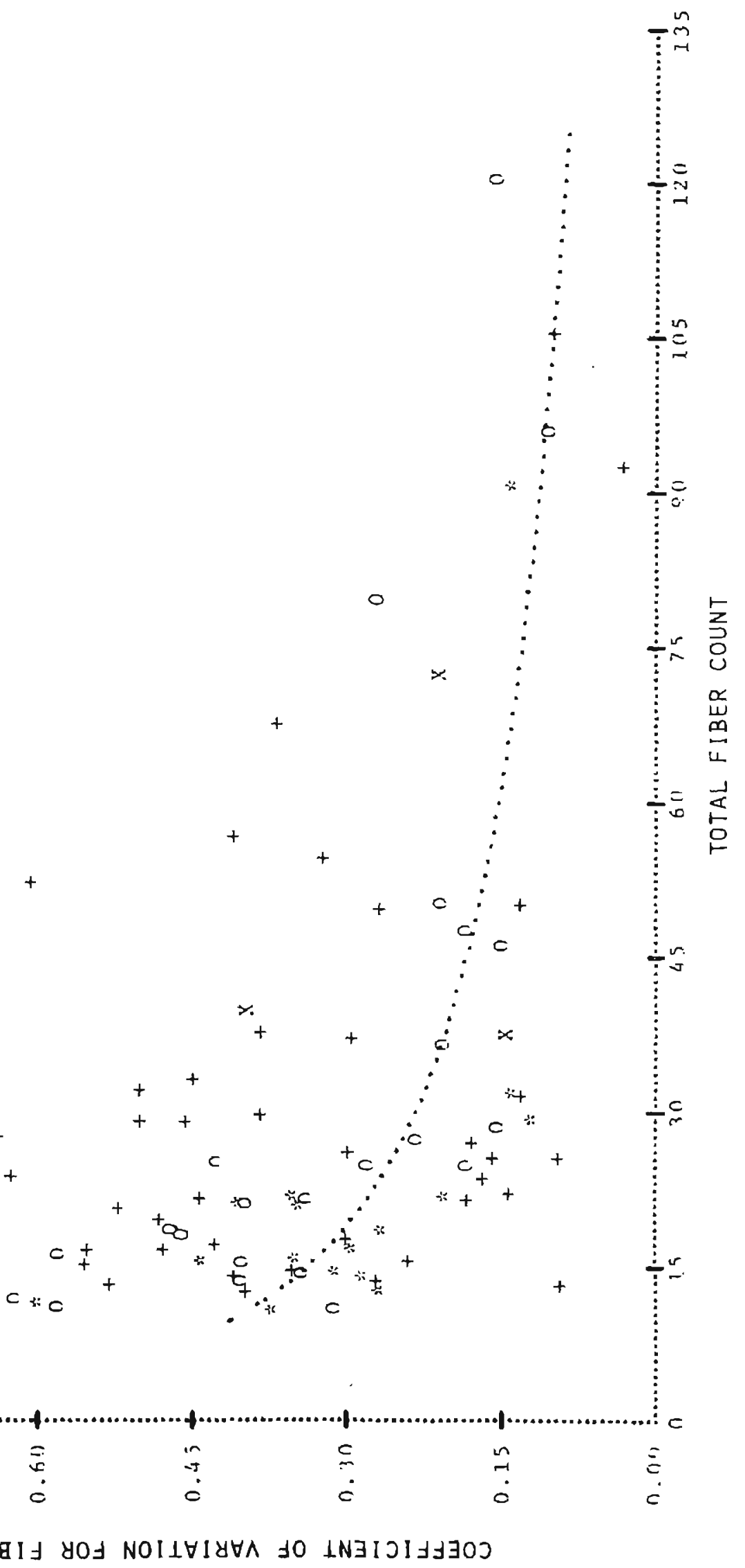




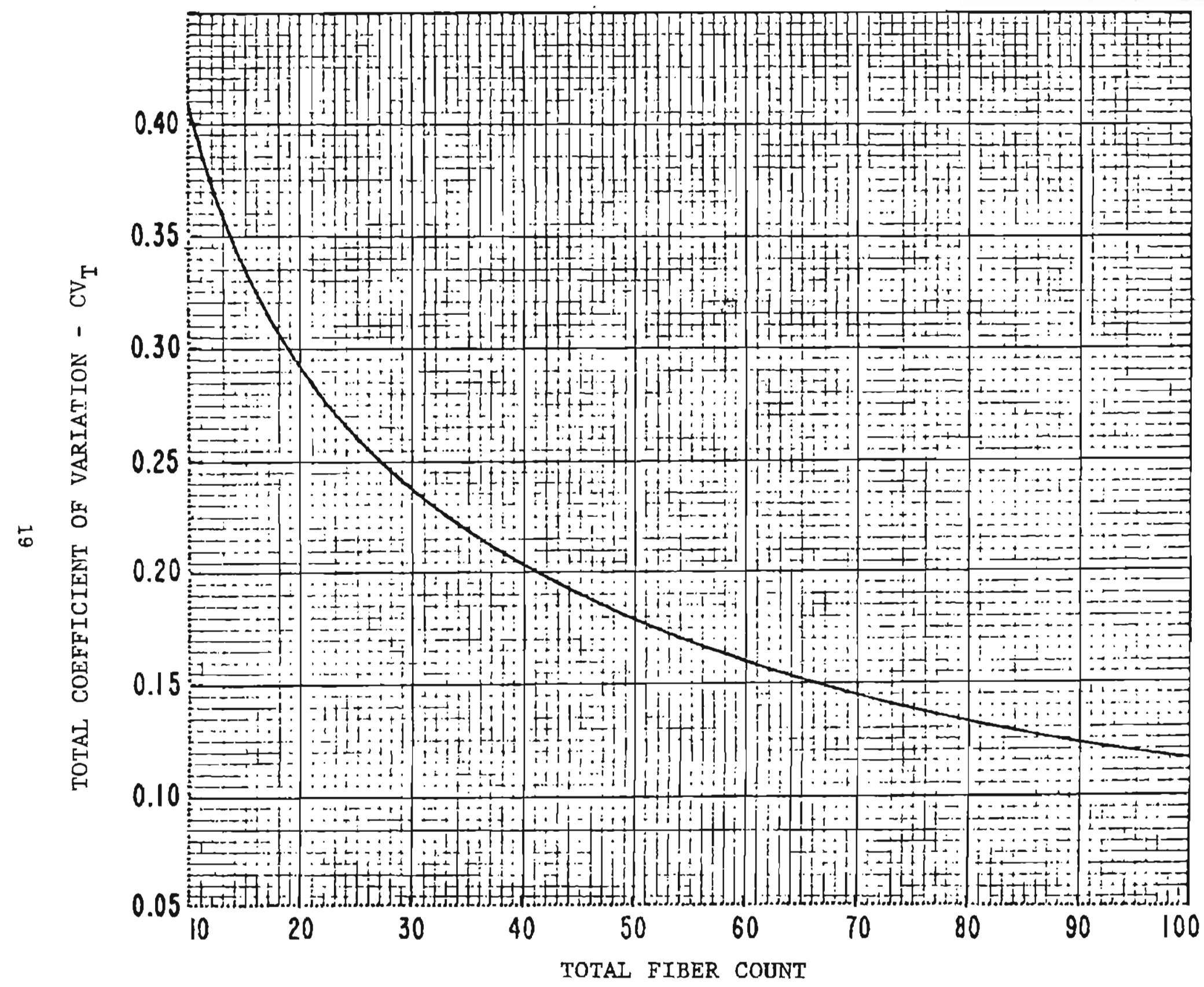

Figure 3. Total coefficient of variation as a function of total fiber count (including pump error) 

MEMORANDUM

To

: Acting Deputy Director

Division of Laboratories and

Criteria Development
DEPARTMENT OF HEALTH, EDUCATION, AND WELFARE

PURI.IC. HEALTH SERVICE

CENTER I:OR DISEAST: CONTTRUL

NATIONAL INSTITUTE FOR OCCUPATIONAL SAFETY AND HEALTH

DATE: October 4, 1972

FROM : Director

Division of Training

SUBJECT: A Systematic Approach to the Standardization of Asbestos Counting

The PAT program has revealed, not unexpectedly, that different counters in different laboratories using similar but not identical microscopes, are obtaining vastly different results in the counting of asbestos fibers. This same phenomena has long been recognized in the counting of impinger dust samples. Some preliminary efforts to obtain agreement by means of training courses and interlaboratory exchanges of personnel have not resolved the problem and the time has come to accept the fact that an intensive, continuing, systematic effort is needed to obtain reasonable uniformity for compliance purposes.

The principal sources of the observed differences are as follows:

1. Difference in technique and observing ability among microscopists.

2. Small, but significant differences in microscopes meeting the basic specification.

Based on the program of the National Coal Board to standardize the counting of thermal precipitator samples of coal dust, the following procedure is recommended:

1. All microscopists who are doing the actual counting for compliance determination should be brought together for an "asbestos counting workshop" at least quarterly.

2. Each microscopist should count each of the same series of slides and the results compared. All microscopes used should be identical.

3. Differences between counters should be resolved, as far as possible, by side by side counting of the same field by different counters.

4. Steps 2 and 3 should be repeated several times to identify persisicnt outliers and to narrow the range of disagreement. 

APPENDDX A.

NIOSH ANALYTICAL METHOD \# P\&CAM 239

ASBESTOS FIBERS IN AIP 


\section{CONTENTS}

Page

1. Principle of the Method............. 27

2. Range and Sensitivity .............. 28

3. Interferences .................. 28

4. Precision and Accuracy ............. 29

5. Advantages and Disadvantages of the Method .. 33

6. Apparatus ...................... 33

7. Reagents ................... 36

8. Procedure ....................... 36

9. Calibration and Standards ............ 43

10. Calculations .................. 47

11. References................... 48 


\section{LIST OF FIGURES}

Figure 1. Optimum sampling times for airborne asbestos where microscopic field area $=0.003 \mathrm{~mm}^{2}$.

Figure 2. Optimum sampling times for airborne asbestos where microscopic field area $=0.006 \mathrm{~mm}^{2}$.

Figure 3. Total coefficient of variation as a function of total fiber count.

Figure 4. Nomogram of optimum sampling times for airborne asbestos fibers in concentrations of 1 to $10 \mathrm{fibers} / \mathrm{cm}^{3}$.

Figure 5. DONOT COUNT, fiber crosses both left and right sides.

Figure 6. COUNT, as one fiber.

Figure 7. COUNT, as " $1 / 2$ fiber," fiber crosses left side and one end lies within count area.

Figure 8. COUNT, as "1/2 fiber," fiher crosses bottom side and one end lies within count area.

Figure 9. DO NOT COUNT, fiber crosses two sides.

Figure 10. DO NOT COUNT, fiber crosses two sides (bottom left corner). 
1. PRINCIPLE OF THE METHOD

1. 1 This method describes the equipment and procedures for collecting, mounting, and counting asbestos fibers on cellulose ester membrane filters in the evaluation of personal samples of airborne asbestos fibers. The purpose of the method is to determine an employee's index of exposure to airborne asbestos fibers. The method is primarily a personal monitoring technique, but can be used for. area monitoring.

1. 2 The sample is collected by drawing air through a membrane filter by means of a battery powered personal sampling pump. The filter is transformed from an opaque solid membrane to a transparent optically homogeneous gel. The fibers are sized and counted using a phase-contrast microscope.at 400-450X magnification.

1. 3 Definitions. Asbestos fibers for counting purposes means a particulate which has a physical dimension longer than 5

micrometers and with a length to diameter ratio of 3 to 1 or greater. Asbestos includes chrysotile, cummingtonite-grunerite (amosite), crocidolite, fibrous tremolite, fibrous anthophyllite, and fibrous actinolite.

1.4 Any laboratory attempting to use this procedure should have at least one counter attend a training course conducted by an experienced proficient laboratory. Novice untutored counters, using only published instructions, can easily obtain counts of half those performed by experienced proficient counters. Large differences between laboratories can be caused by: 1) differences in technique and observing ability among counters and 2) small, but significant, differences between microscopes meeting the basic specifications of Section 6. 2 . The following procedures are recommended;

1.4.1 All microscopists who perform asbestos counting should meet together for an "asbestos counting workshop" at least quarterly. This is best accomplished with counters from several laboratories using their own microscopes. 
1.4.2 Each microscopist should count the same series of slides and with the results being compared.

1.4.3 Differences between counters should be resolved with side-by-side counting of the same fields by the different counters.

1.4. 4 Individuals who are found to be persistent outliers over several sessions should be encouraged to seek other tasks in their respective laboratories.

\section{RANGE AND SENSITIVITY}

2.1 The usable range is primarily a function of sample volume, microscope count field area, and background airborne particulates. The influence of the ve variables is discussed in 8.1.3. For a microscope count field area of $0.003 \mathrm{~mm}^{2}$ (see Figure 1) and a pump flow rate of $1.7 \mathrm{lpm}$, the optimal fiber densities would be produced over the range of $0.4 \mathrm{fiber} / \mathrm{cm}^{3}$ (8-hour sample) to about 60 fibers $/ \mathrm{cm}^{3}$ (15-minute sample). For a field area of $0.006 \mathrm{~mm}^{2}$ (see Figure 2) and a pump flow rate of $1.7 \mathrm{lpm}$, the optimal range is $0.2 \mathrm{fiber} / \mathrm{cm}^{3}$ ( 8 -hour sample to about 30 fibers $/ \mathrm{cm}^{3}(15-$ minute sample). In each case the optimal detection limits are inversely proportional to pump flow rate.

The upper detection limit can be extended by using sample times less than 15 minutes or using lower flow rates. The lower detection limit can be extended by increasing the flow rate up to about. $2.51 \mathrm{pm}$. Filter surface fiber densities less than optimal (less than about 0.5 to 1.0 fiber per count field) are still adequate, but will lead to decreased precision for the method (increased coefficient of variation, see Section 4).

The minimum total fiber count in 100 fields considered adequate for reliable quantitation is 10 fibers. Thus, the lower limit of reliable quantitation is 0.1 fiber $/ \mathrm{cm}^{3}\left(100,000\right.$ fibers $\left./ \mathrm{m}^{3}\right)$. For this level, a flow rate of about $2.5 \mathrm{lpm}$ is recommended. For a field area of $0.003 \mathrm{~mm}^{2}$, the minimum sample time would be about 2 hours. For a field area of $0.006 \mathrm{~mm}^{2}$, the minimum sample time would be about 1 hour.

2. 2 This method considers only fibers with a length to diameter ratio of 3 to 1 or greater, and a length greater than 5 micrometers.

\section{INTERFERENCES}

In an atmosphere known to contain asbestos, all particulates with a length to diameter ratio of 3 to 1 or greater, and a length greater than 5 micrometers 
should, in the absence of other information, be considered to be asbestos fibers and counted as such.

\section{PRECISION AND ACCURACY}

4. 1 In the past decade there have appeared a number of articles examining sources of variation in the asbestos sampling and counting procedure. These include: Lynch et al. (11.1), Weidner and Ayer (11.2), Conway and Holland (11.3), Leidel and Busch (11.4), Beckett and Attfield (11.5), and Rajhans and Bragg (11.6). The sources of variation will be discussed by stages in the membrane filter evaluation procedure.

4. 2 Sources of Variation in the Sampling. Process. The se include variations in pump flow rate, proximity of the filter to the employee's body, and filter location (left to right) in the employee's breathing zone.

4. 2. 1 Section 9. 1 requires that the personal sampling pump be calibrated with sufficient accuracy such that the $95 \%$ confidence limits on the flow rate are $\pm 10 \%$. This is equivalent to a coefficient of variation (CV) of about $5 \%$. However, this $\mathrm{CV}$ makes a negligible contribution to the total $\mathrm{CV}$ for the method due to the relatively large CV of the counting procedure.

4.2. 2 Conway and Holland (11.3) concluded that positioning of the filter cassette on the wearer (regarding the angular portions of the filter and their proximity to the wearer) is not a significant factor in determining the fiber distribution on filters.

4.2. 3 Weidner and Ayer (11.2) concluded that there is no appreciable difference between samples collected on either the right or left sides of a breathing zone or between samples collected side-by-side, especially for samples with concentrations less than 2.5 fibers $/ \mathrm{cm}^{3}$.

\section{3 Sources of Variation in the Counting Procedure}

4. 3.1 Random variations exist in the fiber distribution on a filter wedge (intra-wedge variability). The industrial hygiene literature has seen considerable debate in the last 20 years concerning whether or not the distribution of mineral dust or asbestos fibers on a filter surface is adequately described by a Poisson distribution probability density function. Leidel and Busch (11.4) found excellent agreement between empirical error variance and theoretical variance calculated from the assumption of Poisson distributed true counts. They concluded that there was not excessive variation among count fields for 
a filter wedge and that clumping of fibers (non-random coalcscence) did not occur.

4.3.2 Variations exist in the fiber distribution on the total filter surface (inter-wedge variability) due to the random or non-random distribution of fibers across the total surface of the filter. This type of variation is easily confused with intra-wedge variations. The count procedure does not require counting of multiple sectors of the filter. There may be significant differences between average counts for different wedges, or the fiber distribution variations for the total filter surface may be greater than the variations of the Poisson distribution. If either of the se occur experimentally, one must use the experimental variations to estimate the minimum precision of the count procedure. The minimum precision is governed by the variations of the fiber distribution on the total surface of the filter.

Conway and Holland (11.3) concluded the distribution of fibers or filters is not uniform and the distribution of fiber counts is more disperse than Poisson. For their filters which had significant variations in fiber concentrations between sectors (as much as $50-60 \%$ of the total filter mean) they described the following relation for the standard deviation of the total number of fibers counted on a wedge $(\mathrm{N})$

$$
\text { empirical } s(\mathrm{~N})=1.6(\mathrm{~N})^{1 / 2}
$$

where $N$ is about 100. The Poisson standard deviation would be:

$$
\text { Poisson } \sigma(N)=(N)^{1 / 2}
$$

Rajhans and Bragg (11.6) in Series I of their study found significant variation between filter segments and rejected the Poisson distribution for the total filter surface. However, in Series II of their study, utilizing various experimental. modifications, they found no significant variation between filter segments and no reason to reject the assumption of Poisson dịstributed fiber counts.

4.3.3 Systematic variations due to differences between microscopes was studied by Leidel and Busch (11.4). In their study using five different brands of microscopes they found no significant differences among, four, but the fifth gave counts approximately $45 \%$ higher on the average than the other four. 
4.3.4 Variations due to differences between counters should be examined at three levels: experienced counters occasionally counting, experienced counters routinely counting, and inexperienced (new or untutored) counters. Leidel and Busch (11.4) studied five experienced counters, with one counting only occasionally. There were no significant differences among three of the counters, but a fourth was $16 \%$ lower than the first three. The fifth, who occasionally counted, averaged $27 \%$ higher than the first three.

Conway and Holland (11.3) studied three experienced counters and three inexperienced counters. They found statistically significant differences between the means of both the experienced and inexperienced counters that typically were in the range plus or minus 5 to $15 \%$. They concluded that experience as a fiber counter is not a significant parameter affecting intercounter variations.

Rajhans and Bragg (11.6) found no significant differences among means of five experienced counters in Series I of their study. But in their carefully controlled Series II an analysis of variance showed significant variations between counters that were plus or minus 1 to $15 \%$.

4.3.5 Variations between laboratories are most likely due to systematic biases and are not a significant additional source of random variations. Any additional variations are most likely due to differences in counting technique. Beckett and Attfield (11.5) observed that standard. counters improved greatly after personal instruction; also new counters, after instruction, tended to overcompensate and get exceedingly high counts. Additionally, they found that counts from an experienced laboratory that had not had contact with other laboratories performing the same analysis were as far from the standard values as were the counts by new counters.

4. 4 Sources of variations between samples taken at different times on one employee during one work shift can affect the exposure estimate for that employee. These are primarily due to a) differences in exposure concentrations during the day, b) differences in location of the employee within the plant, and c) differences in work operation performed by the employee during the day. These sources of variation can be controlled by proper choice of sampling strategy. Refer to Leidel and Busch (11.7) and Leidel, Busch and Lynch (11.8) for an extended discussion of sampling strategies. Interday temporal variations can affect the exposure estimates obtained on different days. Refer to Leidel, Busch, and Crouse (11.9) for a discussion of this type of variation. 
4.5 Until recently, the total coefficient of variation $\left(\mathrm{CV}_{\mathrm{T}}\right)$ for the sampling and counting procedure was best estimated from the work of Conway and Holland $(11,3)$. The conclusions of their study included:

1. The precision of their procedure for filters not containing an abundance of fine fibers can be estimated by a (coefficient of variation) of $16.2 \%$. This value includes variation among counters and observed interaction effects.

2. The accuracy of the procedure for similar filters may be estimated for a 100 -fiber count by a (coefficient of variation) of $21.4 \%$. This assumes that the contribution of the overall variance from the nonuniform fiber distribution is additive.

3. A high percentage of very fine fibers on the filter can significantly affect the standard deviation and confidence limits for counts by different counters. After combining variations in fiber concentrations over the entire filter with those for different counters it was concluded:

a. For filters with a low concentration of fine fibers, the (coefficient of variation) is estimated at $21 \%$ and the $95 \%$ confidence interval is $\pm 43 \%$.

b. For filters with a high concentration of fine fibers, the (coefficient of variation) is estimated at $25 \%$ and the $95 \%$ confidence interval is $\pm 50 \%$.

Lynch, Kronoveter, and Leidel (11.1) have also reported on variations of the method. Their intralaboratory study utilized the data from a large number of dust counts made by different methods by experienced counters over a period of years in an epidemiologic study of the asbestos products industry. They concluded that the standard deviation of counts of fibers longer than 5 micrometers on membrane filters could be estimated from the relation $\sigma=(\mathrm{N})^{0.591}$. Thus for counts of about 100 fibers, the coefficient of variation could be estimated at about $15.2 \%$ and the $95 \%$ confidence limits at $\pm 30.4 \%$. These values are lower than the values reported by Conway and Holland (11.3).

Recently the Johns-Manville Corporation conducted an in-house investigation of the asbestos count method (11.10). Their study data contained total fiber counts for over 100 filters with each filter counted by two to five counters. From the Johns-Manville data, Busch et al. calculated over 100 estimates of the count $\mathrm{CV}$ for the method (11.11). The NIOSH CV estimates included random intrafilter variations and intercounter variations, but did not include random pump flow rate variations. It was found that the count coefficient of variation (all random variations except for pump variations) was a 
function of the total fiber count. NIOSH then included a CV of 0.05 for random pump variations (see Section 9.1) in the CV -estimator equation to obtain a $\mathrm{CV}_{\mathrm{T}}$-estimator. The $\mathrm{CV}_{\mathrm{T}}$-estimator line is plotted on Figure 3 for total fiber counts in the range 10 to 100 fibers. Or the following equation can be used:

$$
\begin{aligned}
& \mathrm{CV}_{\mathrm{T}}=\left[\left(\mathrm{CV}_{\mathrm{F}}^{\prime}\right)^{2}+(0.05)^{2}\right]^{1 / 2} \\
& \text { Where } \mathrm{CV}_{\mathrm{F}}^{\prime}=\text { antilog }{ }_{10}\left[0.0595-0.3241(\log \mathrm{FB})-0.01585\left(\log ^{2} \mathrm{FB}\right)\right]-0.12
\end{aligned}
$$

and FB is total fiber count as discussed in Section 10.

Figure 3 demonstrates that for a total fiber count of 100 , the best $\mathrm{CV}_{\mathrm{T}}$ is attainable with the appropriate sampling times given in 8.1 .3 and the count rules in 8.3 .9 . When making decisions regarding compliance with the OSHA asbestos exposure standards in 29 CFR 1910.1001, the statistical procedures given in this report should be followed. The procedures are based on statistical theory and assumptions given in $(11,7,11.8)$.

Because of the possibility of systematic biases due to differences between microscopes, counters, and laboratories as discussed above, it is strongly recommended that any laboratory counting asbestos should participate in an interlaboratory quality control program that includes the counting of standard reference filters. These standard filters are available from NIOSH through the Proficiency Analytical Testing (PAT) Program. The PAT Program is used by the American Industrial Hygiene Association (AIHA) as part of its Laboratory Accreditation Program. Each laboratory's quality control program must include protocols for routinely adjusting and calibrating sampling and counting equipment plus training and evaluation programs for counters.

\section{ADVANTAGES AND DISADVANTAGES OF THE METHOD}

5.1 The method is intended to give an index of employee exposure to airborne asbestos fibers of specified dimensional characteristics.

5. 2 It is not meant to count all asbestos fibers in all size ranges or to differentiate asbestos from other fibrous particulates.

\section{APPARATUS}

\section{1 Sampling Equipmerit}

The personal sampling equipment train consists of: 1) personal sampling pump, 2) tubing, 3) clothing spring clip, 4) tubing-to-field monitor metal adaptor, and 5) field monitor (filter and holder). 
6. 1.1 Personal Sampling Pump. The pump must be capable of sampling at 1.0 to 2.5 liters per minute (1pm) against a flow resistance of 7.5 inches of water $(1.4 \mathrm{~cm} \mathrm{Hg})$ for 8 continuous hours on a fully charged battery.

6.1.2 Tubing. Laboratory tubing such as rubber or plastic with 6- $\mathrm{mm}$ bore and about $100 \mathrm{~cm}$ length.

6. 1. 3 Clothing Spring Clip. The clip attaches the rubber tubing to the lapel or shirt of the individual being monitored.

6.1.4 Tubing-to-field Monitor Adaptor. A short metal adaptor with ridges on one end to grip the inside of the tubing. The other end is designed for a pressure fit into the field monitor.

6.1.5 Field Monitor (Filter and Holder). Millipore or equivalent. The unit consists of: 1) a three section styrene plastic case for Aerosol monitoring, 2) a 37-mm diameter plain white cellulose ester membrane filter, Millipore AA (pore size of 0.8 micrometer) or equivalent, 3) a support pad, and 4) two plastic sealing caps. If a large number of samples are to be taken, it may be less expensive to reuse the plastic cases. Great care must be taken in the cleaning and reassembly process. The outside mating surfaces of the field monitors may be covered with a "shrink-fit" band to provide proper sealing and a writing surface for filter identification.

\section{2 Optical Equipment and Microscope Features}

6.2.1 Microscope body with binocular head.

6.2.2 10X Huygenian eyepieces are recommended. Other eyepieces can be substituted if necessary. Wide field eyepieces can be used; however, wide field eyepieces may yield a count field area less than $0.003 \mathrm{~mm}^{2}$ with the Porton reticle. This is not always desirable from the standpoint of obtaining optimum sampling times (see Section 8.1.3). If wide field eyepieces are used, it is preferable to use the Patterson Globe and Circle reticle to obtain a larger count field area.

6. 2. 3 Köehler illumination (preferably built in with provisions for adjusting light intensity).

6.2.4 A Porton reticle is recommended. Others such as the Patterson Globe and Circle can be substituted.

6. 2.5 Mechanical stage 
6. 2.6 Phase-Contrast condenser with a numerical aperature (N. A.) equal to or greater than the N.A. of the objective.

6.2.7 40-45X phase contrast achromatic objective (N. A. 0.65 to $0.75)$.

6.2.8 Phase-ring centering telescope or Bertrand lens.

6.2.9 Green filier, if recommended by microscope manufacturer.

6.2.10 Stage micrometer with $0.01 \mathrm{~mm}$ subdivisions.

6.2.11 For general guidance on phase contrast microscopy, consult Needham (11.12), Clark (11.13) and McCrone (11.14).

6. 3 Filter Mounting Equipment. Experience has shown that certain equipment is useful for efficient sample mounting. The following items are recommended for extracting and mounting a portion of the filter for counting.

6.3. 1 Microscope slides. 2.5 by $7.5 \mathrm{~cm}$ glass slides are most commonly used. Sample number, data, initials, etc, , can be conveniently written on a frosted end slide.

6.3.2 Cover Slips. Cover slips are a necessary part of the slide mount and optical system. The shape should be appropriate for the size of the filter wedge. The appropriate cover slip depends upon the objective to be used. Ordinarily objectives are optically corrected for a \#1-1/2 (0.17 millimeter) thickness cover slip. Improper cover glass thickness will detract from the final image quality.

6.3.3 Scalpel. A scalpel is needed to cut out a portion of the filter to be examined. A number-ten-curved blade scalpel is recommended.

6.3.4 Tweezers. A pair of fine-tipped tweezers is used to remove the membrane filter slice from the field monitor and place it upon the slide.

6.3.5 Lens Tissue. To insure cleanliness, a lint-free tissue is recommended. This tissue should also be used for wiping mounting tools and for cleaning slides and cover slips.

6.3.6 Glass Rod. A fire-polished glass rod may be used to spread the mounting solution on the slide. 
6.3.7 Wheaton Balsam Bottle. This special glass container has a glass top which minimizes contamination of the mounting solution. A glass rod is included for dispensing the solution.

\section{REAGENTS}

Chemicals should be reagent grade, free from particles and color, conforming to the specifications of the Committee on Analytical Reagents of the American Chemical Society, where such specifications are available.

7.1 Dimethyl phthalate

7. 2 Diethyl oxalate

Avoid getting the mounting solution on the skin. Wash skin proniptly with soap and water if skin contact occurs.

8. PROCEDURE

8.1 Sampling

8.1.1 General Information

Guidelines for the monitoring of employee exposures to industrial atmospheres are given in Reference (11.8). The Federal requirements for monitoring employee exposure to airborne asbestos are found in 29 CFR 1910.1001.

8.1.2 Mounting the Sampling Pump on the Worker

Fasten the sampling pump to the worker's belt and fasten the field monitor to the lapel or shirt front (as close to the breathing zone as is practical). Remove the top cover of the plastic monitor, then invert the monitor making certain the exposed filter is facing downward. Turn the pump on and adjust to the calibrated flow rate ( 1.0 to $2.5 \mathrm{lpm})$. Record the following information in a logbook.

1. Filter number

2. Pump start time and date

3. Flow rate

4. Subject's name and job title

5. Type of operation or process 
6. Ventilation controls and is the worker wearing a respirator NIOSH-approved for asbestos?

The pump should be checked periodically during the sampling period for proper operation and flow rate.

\section{1.3 Optimum Sampling Times}

The requirement for the minimum count of 100 fibers or 20 fields in 8.3 .9 was determined to be the best compromise to achieve adequate precision for the airborne fiber estimate and reasonable counting times. An optimum fiber density of about 1 to 5 fibers per microscope count field is recommended. To estimate appropriate sampling times for feasible counting and optimal counting, one must consider the following constraints:

a) microscope count field area (generally 0.003 to $0.006 \mathrm{~mm}^{2}$ )

b) pump flow rate (typically $2.51 \mathrm{pm}$ maximum)

c) average airborne fiber concentrations

d) counting rule range of $20^{-}$to 100 fields

e) adequate fiber density to obtain a minimum count of 10 fibers in 100 fields, which is the least total fiber count that yields an acceptable count precision

f) background airborne particulate levels that can reduce the count precision due to an obscuring of fibers on the filter surface

The preceding constraints were considered in drawing Figures 1 and 2. These figures were developed from the following relationship:

$$
\text { Minutes }=\frac{(F B / F L)(E C A / M F A)}{(F R)(A C)(1000)}
$$

where: $\mathrm{FB} / \mathrm{FL}=1$ to 5 fibers $/$ field

$\mathrm{ECA}=$ effective collecting area of filters $\left(855 \mathrm{~mm}^{2}\right.$ for $37-\mathrm{mm}$ filter with effective diameter of $33 \mathrm{~mm}$ )

MFA = microscope field area (generally 0.003 to $0.006 \mathrm{~mm}^{2}$ )

$\mathrm{FR} \quad=$ pump flow rate (generally 1.0 to $2.5 \mathrm{lpm}$ )

$\mathrm{AC}=$ air concentration of fibers in fibers $/ \mathrm{cm}^{3}$.

Figure 1 (microscope field area $=0.003 \mathrm{~mm}^{2}$ ) and Figure 2 (microscope field area $=0.006 \mathrm{~mm}^{2}$ ) show optimum and 
feasible sampling times for a pump flow rate of $1.7 \mathrm{lpm}$. Each individual responsible for sampling asbestos should prepare a similar chart for his particular pump flow rate and microscope field area before sampling is performed to aid in estimating proper sampling times. On Figures 1 and 2 the areas with solid shading lines are generally the optimum conditions for counting. The broken shading lines are for conditions very close to optimal.

However, feasible counting conditions may extend down to about 0.1 fiber/field and above 5 fibers/field. Recommended sampling times are most strongly influenced by background airborne particulate levels, once all the other constraints have been estimated. For heavy particulate levels, it may be necessary to limit each filter to about 60 to 180 minutes sampling duration. Each individual responsible for sampling should work closely with the microscopist to attain as high as possible filter surface fiber densities (up to about 5 fibers/field). while avoiding filter surface background particulate levels that create very difficult or impossible counting conditions. If one has very little idea of airborne fiber and particulate levels, the best procedure is to take several long samples (as one 8 -hour or two consecutive 4-hour samples) in conjunction with several short samples (as four consecutive 2-hour or eight consecutive 1-hour samples). If the longer samples prove very difficult to count, the microscopist will have the shorter samples to fall back on:

From Figures 1 and 2, it can be seen that there are certain sampling times which will yield optimum fiber densities on the filter for almost all airborne fiber concentrations from 1 to 10 fibers $/ \mathrm{cm}^{3}$. The se optimum times have been calculated and are presented in Figure 4. Note that the optimum times given by Figure 4 are approximate and can be varied by as much as $\pm 25 \%$. The nomogram is intended as a guide to be used where no prior knowledge of the air concentration is available.

\section{1.4 End of Sampling Period}

Remove the field monitor, replace the plastic top cover and the small end caps, and store the monitor. Always shut off the pump when changing monitors to avoid contaminating or damaging the pump. Record the pump shutoff time and flow rate in the logbook. 


\section{1.5 Blanks}

With each batch ( 25 to 50 filters) of samples sent for analysis submit two unopened field $m_{2}$ onitors which have been subjected to the same treatment as the samples except that they were not exposed to the sampling environment. Label these as blanks. If the blanks yield fiber counts greater than 5 fibers/100 fields, then the entire sampling procedure should be examined carefully for the cause of contamination. The mounting solution of Section 8.2 . 1 should also be examined for contamination and/or crystal growth.

\section{1.6 Shipping}

The field monitors in which the samples are collected should be shipped in a rigid container with sufficient packing material to prevent crushing.

\subsubsection{Numbers of Samples}

When sampling for the Federal ceiling standard of 10 (fibers $>5 \% \mathrm{~m}$ ) $/ \mathrm{cm}^{3}$, [29 CFR 1910.1001(b)(3) effective July 7,1972 ] only one sample (15-minute maximum duration) is theoretically necessary.

However, several samples should be taken during expected periods of peak air concentrations to allow for detection of gross sampling or counting errors.

When sampling for determination of noncompliance with the Federal 8-hour TWA standard of 2 (fibers $>5 \mu \mathrm{m}) / \mathrm{cm}^{3}$, [29 CFR 1910.1001(b)(2)] one should continuously sample a large portion of the work day as is feasible for airborne concentrations of about 2 to 10 fibers $/ \mathrm{cm}^{3}$. However, for a lower airborne concentration such as $0.5 \mathrm{fiber} / \mathrm{cm}^{3}$ one sample might require 4 to 8 hours sampling time in order to get the proper filter fiber density (Section 8.1.3). For this situation the 8-hour TWA exposure would be determined from one 8-hour or two 4-hour samples as appropriate.

\section{2 Sample Preparation}

\subsubsection{Preparation of Mounting Solution}

A very important part of the sample evaluation is the mounting process. This process involves a special mounting medium of prescribed viscosity. The proper viscosity is important in order to expedite filter dissolving and still minimize particle 
migration. After the sample has been mounted, an elapsed time of approximately sixty minutes is needed before the sample is ready for evaluation.

Combine the dimethyl phthalate and diethyl oxalate in a one to one ratio by volume and pour into a Wheaton balsam bottle. Add approximately 0.05 grams $(0.045$ to 0.055$)$ of the new membrane filter per milliliter of solution to reach the necessary viscosity. The mixture must be stirred periodically until the filters have dissolved and a homogeneous mixture is formed. The normal shelf life of the mounting solution is about three months. Twenty milliliters of mounting solution will prepare approximately 300 samples.

\subsubsection{Sample Mounting}

Cleanliness is important! A dirty working area may result in sample contamination and erroneous counts. The following steps should be followed when mounting a sample.

8.2.2.1 Clean the slides and cover slips with lens tissue. Lay each slide down on a clean surface with the frosted end up. It is a good practice to rest one edge of the cover slip on the slide and the other edge on the working surface. By doing this, you keep the bottom surface (the one which contacts the filter) from becoming contaminated.

8.2.2.2 Wipe all the mounting tools clean with lens tissue and place them on a clean surface (such as lens tissue). All tools should be wiped clean prior to mounting each..sample.

8.2.2.3 Using the glass rod supplied with the Wheaton balsam bottle, apply a drop of mounting solution onto the center of the slide. It may be necessary to adjust the quaritity of solution so that the correct amount, after the cover slip has been placed on top, results in the solution extending only slightly beyond the filter boundary. If the quantity is greater than this, particle migration may occur.

8.2.2.4 Using another glass rod, spread the mounting media into a triangular shape. The size of this triangle should coincide with the dimension of the filter wedge. 
8.2.2.5 Separate the middle and bottom sections of the field monitor case to expose the filter. Cut a triangular wedge from the center to the edge of the filter using the scalpel: The size of the wedge should approximate one-eighth of the filter surface. The filter can be very carefully removed from the cassette for cutting, but this should only be done with great care.

8.2.2.6 Grasp the filter wedge with the tweezers on the perimeter of the filter which was clamped between the monitor case sections. Do not touch the filter with your fingers. Place the wedge, sample side up, upon the mounting medium.

8. 2.2.7 Pick up a clean cover slip with tweezers and carefully place it on the filter wedge. Once this contact has been made, do not reposition the cover slip.

8. 2.2.8 Label the slide with the sample number and current date before proceeding to the next filter. On the bottom (backside) of the slide trace the perimeter of the filter wedge with a felt tip marking pen. This will enable the counter, after the filter has become transparent, to stay within the filter perimeter when counting.

8.2.2.9 The sample should become transparent within fifteen minutes. If the filter appears cloudy, it may be necessary to press very lightly on the cover slip. This is rarely necessary; however, counting should not be started until an hour after the mounting. This allows the microscopic texture of the filter to become invisible to microscope viewing.

8. 2. 2.10 Discard the sample mount after two days if it has not been counted. Crystals appearing similar to asbestos fibers may begin to grow at the mounting media/air interfaces. They seldom present any problems if the slide is examined before two days. In any case, stay away from the filter's edges when counting and sizing.

\section{8, 3 Counting of Fibers}

8.3.1 Place the slide on the mechanical stage and position the center of the wedge under the objective lens and focus upon the sample. Start counting from one end of the wedge and 
progress along a radial line to the other end (count in either direction from perimeter to wedge tip). Random fields are selected, without looking into the eyepieces, by slightly advancing the slide in one direction with the mechanical stage control.

8.3.2 It is essential to continually scan over a range of focal planes (generally the upper 10 to 15 micrometers of the filter surface) with the fine focus control during each field count. This is especially necessary for asbestos fibers due to their impaction into the filter matrix.

8.3.3 On most airborne samples asbestos fibers will generally have fiber diameters less than one micrometer. Therefore, it is necessary to look carefully for faint fiber images.

8.3.4 Regularly check phase ring alignment.

8.3.5 When an agglomerate (mass of material) covers a significant portion of the field of view (approx $1 / 6$ or greater) reject the field and select another. (Do not include it in the number of fields counted.) However, report the fact as it may have meaning on other data collection.

8,3.6 Bundles of fibers are counted as one fiber unless both ends of the fiber can be clearly resolved.

8.3.7 Count only fibers with a length to width ratio greater than or equal to $3: 1$.

8.3.8 Count only fibers greater than 5 micrometers in length. (Be as accurate as possible in accepting fibers near this length). Measure curved fibers along the curve to estimate the total length.

8.3.9 Count as many fields as necessary to yield a total count of at least 100 fibers. Exceptions: a) count at least 20 fields even if you count more than 100 fibers, and b) stop at 100 fields even if you haven't reached 100 fibers.

8.3.10 For fibers that cross either one or two sides of the counting field, the following procedure is used to obtain a representative count.

COUNT any fiber greater than 5 micrometers in length, that lies entirely within the counting area. COUNT as " $1 / 2$ fiber" any fiber with only one end lying within the counting area. DO NOT COUNT any fiber crossing any two sides. 
Reject and do not count all other fibers, Réfer to Figure 5 through 10. Note that the fibers in Figure 5 through 10 are not representative of the appearance of most asbestos

fibers. Most fibers have a very faint image.

\section{CALIBRATION AND STANDARDS}

\section{1 Sampling Train Calibration}

The accurate calibration of the sampling pump is essential to the correct calculation of the air volume sampled. The frequency of calibration is dependent on the use, care, and handling to which the pump is subjected. Pumps must be recalibrated if they have just been repaired, misused, or received from the manufacturer. If the pump receives hard usage, more frequent calibration may be necessary. Ordinarily pumps should be calibrated in the laboratory both before they are used in the field and after they have been used to collect a large number of field samples.

The accuracy of calibration is dependent upon the type of instrument used as a reference. The choice of a calibration instrument will depend largely on where the calibration is performed. For laboratory testing, a 1-liter buret used as a soapbubble flow meter or wet-test meter is recommended. Other standard calibrating instruments, such as a spirometer, Marriott's bottle, or dry gas meter can be used. The calibration should be of sufficient precision such that the $95 \%$ confidence limits on the flow rate are $\pm 10 \%$ ( $95 \%$ of the flow rates will fall with $上 10 \%$ of the calibrated value).

Instructions for calibration with the soapbubble flow meter follow. The sampling train used (pump, hose, filter cassette) in the pump calibration should be the same as the one used in the field.

9.1. I Check the voltage of the pump battery with a voltmeter both with the pump off and while it is operating to assure adequate voltage for calibration. If necessary, charge the battery to manufacturer's specifications.

9.1.2 Fill a beaker with $10 \mathrm{ml}$ of soap solution.

9.1.3 Connect the filter cassette inlet to the top of the buret with length of hose.

9.1.4 Turn the pump on and moisten the inside of the soapbubble meter by immersing the open end of the buret into the soap solution and drawing bubbles up the inside of the buret. Perform this task until the bubbles are able to travel the entire length of the buret without breaking. 
9. 1.5 Adjust the pump rotameter to provide a flow between 1.5 to $2.5 \mathrm{lpm}$.

9.1.6 With a water manometer, check that the pressure drop across the filter is less than 13 inches of water (about 1 inch of mercury).

9.1.7 Start a soapbubble up the buret and measure the time it takes for the bubble to travel a minimum volume of 1 liter.

9.1.8 Repeat the procedure in 9.1 .7 at least three times, average the results, and calculate the calibrated flow rate by dividing the volume traveled by the soap bubble by the elapsed time. If the range between the highest and lowest of the three flow rates is greater than about $0.33 \mathrm{lpm}$, then the calibration should be repeated since it is likely that the precision is not adequate.

9. 1.9. Data required for the calibration include the volume measured, elapsed time, pressure drop, air temperature, atmospheric pressure (or elevation), pump serial number, date, and name of person performing the calibration.

9.1.10 Corrections to the flow rate for pumps with rotameters may be necessary if the pressure (elevation) or temperature where the samples are collected (actual flow rate) differs significantly from that where the calibration was performed (indicated flow rate). Actual flow rates at time of sampling may be calculated for a linear scale rotameter by using the following correction formula (11.8):

$$
Q_{\text {actual }}=Q_{\text {indicated }} \sqrt{\frac{P_{\text {cal }}}{P_{\text {actual }}}} \cdot \frac{T_{\text {actual }}}{T_{\text {cal }}}
$$

where both pressure $(P)$ and temperature $(T)$ are in absolute units such as:

$$
\begin{aligned}
& \text { psia }=\text { psig }+14.7 \\
& \text { deg Rankin = deg Fahrenheit }+460 \\
& \text { deg Kelvin = deg Celsius }+273
\end{aligned}
$$

\subsection{Microscope Setup}

\subsubsection{Porton Reticle and the Counting Field}

The asbestos fiber count procedure consists of comparing fiber length to the diameters of calibrated circles of a 
Porton reticle, and counting all fibers greater than 5 micrometers in length lying within a given counting field area. The Porton reticle is a glass plate inscribed with a series of circles and rectangles. The left half of the reticle is divicled into six rectangles constituting the counting field. The counting field is illustrated in Figures 5 through 10.

9.2.2 Placement in Eyepiece

The Porton reticle is placed inside the Huygenian eyepiece where it rests on the field-limiting diaphragn. If other types of eyepieces are used, it may be necessary to insert a counting collar for retaining the reticle.

The reticle should always be kept clean, since dirt on the reticle is in focus and could complicate the counting and sizing process.

\subsubsection{Stage Micrometer}

The Porton reticle cannot be-used for counting until it has been properly calibrated with a stage micrometer. Most stage micrometer scales are approximately two millimeters long and are divided into units of one-hundredth of a millimeter (ten micrometers).

\subsubsection{Microscope Adjustment}

When adjusting the microscope follow the manufacturer's instructions while observing the following guidelines.

1. The light source image must be in focus and centered on the condenser iris or annular diaphragm.

2. The particulate material to be examined must be in focus.

3. The illuminator field iris must be in focus, centered on the sample, and opened only to the point where the field of view is illuminated.

4. The phase rings (annular diaphragm and phase-shifting elements) must be concentric.

\subsubsection{Porton Reticle Calibration Procedure}

Each eyepiece-objective-reticle combination on the microscope must be calibrated. Should any of the three be changed 
(disassembly, replacement, zoom adjustment, etc.) the combination must be recalibrated. Calibration may change if interpupillary distance is changed. For proper calibration, the following procedure should be followed closely.

With a $10 \mathrm{X}$ objective in place, place the stage micrometer on the mechanical stage, focus the millimeter scale, and center the image. Change to the $40-45 \mathrm{X}$ objective and adjust the first millimeter scale division to coincide with the left boundary of the Porton rectangle. Measure the distance between the left and extreme right boundaries of the Porton rectangle, estimating any portion of the final division. This measurement represents $200 \mathrm{~L}$ units. The rectangle is $100 \mathrm{~L}$ units on the short vertical dimension. The calculated " $L$ " is inserted into the formula $D=L\left(2^{N}\right) 1 / 2$ where " $N "$ is the circle number (indicated on the reticle) and " $D$ " is the circle diameter. Since the circle diameters vary logarithmically, every other circle doubles in diameter. For example, circle number three is twice the diameter of number one; number four is twice the diameter of number two. When the circle sizes have been determined, the counting field area which consists of the left six smaller rectangles, can be calculated from the relation $10,000 \mathrm{~L}^{2}$. This completes the reticle calibration for this specific objective-eyepiece-reticle combination.

\section{Example for Porton Reticle}

The following calibration was obtained for a pair of $10 \mathrm{X}$ Huygenian eyepieces and a $43 \mathrm{X}$ objective:

$200 \mathrm{~L}=0.148 \mathrm{~mm}=148$ micrometers

$100 \mathrm{~L}=0.074 \mathrm{~mm}=74$ micrometers

One L-unit $=0.74$ micrometers

Thus Circle \#1 has a diameter $\mathrm{D}=\mathrm{L}\left(2^{\mathrm{N}}\right)^{1 / 2}=0.74\left(2^{1}\right)^{1 / 2}$ $=0.74(1.414)=1.05$ micrometers.

Then our circle diameter calibration table looks like:

Diameter of Circle \#1 $=1.05$ micrometers

$\# 2=1.48$

$\# 3=2.09$

$\# 4=2.96$

$\# 5=4.19$

$\# 6=5.92$

Field area $=(10,000)\left(\mathrm{L}^{2}\right)=(100 \mathrm{~L})(100 \mathrm{~L})$ $=(0.074)(0.074)=0.0055 \mathrm{~mm}^{2}$ 
Thus fibers with a length greater than a distance halfway between the diameters of the $\# 5$ and $\# 6$ circles would be counled.

If a Patterson Globe and Circle reticle is used, a different calculation procedure is required. The circle diameters are related as follows. The $\# 25$ circle diameter is $(0,1)$ (reticle length).

Thus circle diameters are proportional to the ratio of their numbers. Thus the $\# 20$ circle diameter is $(20 / 25)$ or 0.8 times the \#25 circle diameter.

\section{CALCULATIONS}

10.1 The average airborne asbestos fiber concentration estimated by the filter sample may be calculated from the following formula:

$$
A C=\frac{[(F B / F L)-(B F B / B F L)](E C A)}{(1000)(F R)(T)(M F A)}
$$

where: $\mathrm{AC}=$ Airborne fiber concentration in (fibers $>5 \mu \mathrm{m}) / \mathrm{cm}^{3}$.

$\mathrm{BFB}=$ Total number of fibers counted in the BFL fields of the blank or control filters in fibers $>5 \mu \mathrm{m}$.

$\mathrm{BFL}=$ Total number of fields counted on the blank or control filters.

ECA = Effective collecting area of filter $\left(855 \mathrm{~mm}^{2}\right.$ for a $37-\mathrm{mm}$ filter with effective diameter of $33 \mathrm{~mm}$ ).

$\mathrm{FR}=$ Pump flow rate in liters $/ \mathrm{min}(1 \mathrm{pm})$.

FB = Total number of fibers counted in the FL fields in fibers $>5 \mu \mathrm{m}$.

FL = Total number of fields counted on the filter.

MFA = Microscope count field area in $\mathrm{mm}^{2}$ (generally 0.003 to 0.006 ).

$\mathrm{T} \quad=$ Sample collection time in minutes.

10.2 Recount criteria. It is very desirable for a counter to conduct a "blind recount" for about 1 in every 10 filter wedges (slides) counted. Alternatively a second counter could perform the blind recount. In training sessions for novice counters, the trainee should conduct a blind recount for filter wedges counted by an experienced proficient counter. In all cases we will observe differences between the first and second counts of the same filter 
wedge. Most of the se differences will be due to chance alone, that is, due to the random variability (precision) of the count method. Statistical recount criteria enable us to decide whether observed differences can reasonably be explained due to chance alone or are probably due to systematic differences between counters or microscopes or due to some other biasing factor.

The following recount criterion is for a pair of counts that estimate some airborne fiber concentration $(A C)$ in fiber $/ \mathrm{cm}^{3}$. The criterion is given at the type-I error level. That is, there is a $5 \%$ maximum risk that we will reject a pair of counts for the reason that one might be biased, when the large observed difference is really due to chance.

Reject a pair of counts because one might be biased if:

$$
\left(\mathrm{AC}_{2}-\mathrm{AC}_{1}\right) \text { exceeds } 2.77(\overline{\mathrm{AC}})\left(\mathrm{CV}_{\mathrm{FB}}\right)
$$

where: $A C_{1}=$ lower estimated airborne fiber concentration

$\mathrm{AC}_{2}=$ higher estimated airborne fiber concentration

$\overline{\mathrm{AC}}=$ average of the two airborne concentration estimates

$\mathrm{CV}_{\mathrm{FB}}=$ average $\mathrm{CV}$ for the two concentration estimates which are a function of the total fiber count (FB) in each case. Use the relation in Section 4 or Figure 3.

For a pair of counts on the same filter, reject the pair because one might be biased if:

$$
\left(F B_{2}-F B_{1}\right) \text { exceeds } 2.77(\overline{F B})\left(C V_{\overline{F B}}\right)
$$

where: $F B_{1}=$ lower fiber count on the filter (total fibers)

$$
\mathrm{FB}_{2}=\text { higher fiber count on the filter (total fibers) }
$$

$\overline{\mathrm{FB}}=$ average of the two total fiber counts

$C V_{\overline{F B}}=\mathrm{CV}_{\mathrm{T}}$ for the value $\overline{\mathrm{FB}}$. Use the relation in Section 4 or Figure 3.

\section{REFERENCES}

11.1 Lynch, J. R., K. J. Kronoveter, and N. A. Leidel: "Validity of the Poisson Distribution in Dust Counting," USPHS, (NIOSH unpublished report TR-83) (1968). 
11.2 Weidner, R. B. and H. E. Ayer: "Dust Exposure in Asbestos Processing," Trans. ACGIH, 103-121, San Francisco, CA, (May 1972).

11. 3 Conway, R. E. and W. D. Holland: "Statistical Evaluation of the Procedure for Counting Asbestos Fibers on Membrane Filters," LFE Corporation, Richmond, CA. Prepared for Asbestos Information Assoc/North America, New York, NY (1973).

11.4 Leidel, N. A. and K. A. Busch: "An Evaluation of Phase Contrast Microscopes for Asbestos Counting, " presented at the 1974 American Industrial Hygiene Conference, Miami Beach, Florida, 18 May 1974 (NIOSH unpublished in-house report TR-92).

11. 5 Beckett, S. T. and M. D. Attfield: "Inter-Laboratory Comparison of the Counting of Asbestos Fibers Sampled on Membrane Filters," Annals of Occupational Hygiene, 17: 85-96 (1974).

11.6 Rajhans, G. S. and G. M. Bragg: "A Statistical Analysis of Asbestos Fiber Counting in the Laboratory and Industrial Environment," $\underline{\text { AIHAJ, }} \underline{36}$ (12): 909-915 (1975).

11. 7 Leidel, N. A. and K. A. Busch: "Statistical Methods for the Determination of Noncompliance with Occupational Health Standards, " NIOSH Technical Publication 75-159 (1975).

11.8 Leidel, N. A., K: A. Busch and J. R. Lynch: "Occupational Exposure Sampling Strategy Manual," NIOSH Technical Publication 77-173 (1977).

11.9 Lejdel, N. A., K. A. Busch and W. E. Crouse: "Exposure Measurement Action Level and Occupational Environmental Variability, "NIOSH Technical Publication 76-131 (1975).

11. 10 Comments of the Johns-Manville Corporation with Respect to the Notice of Proposed Rulemaking: Occupational Exposure to Asbestos, Federal Register, October 9, 1975. Submitted to the public record at the U.S. Department of Labor, Occupational Safety and Health Administration (April 1976).

11. 11 Busch, K. A., N. A. Leidel, R. W. Hornung, R. J. Smith: Unbiased Coefficients of Variation for Asbestos Counting Determined from Johns-Manville Data, to be published in the Proceedings of the 1977 Society for Occupational Safety and Environmental Health Conference on "Occupational Exposures to Fibrous and Particulate Dust and Their Extension to the Environment."

11.12 Needham, G. H.: "The Practical Use of the Microscope," Charles C. Thomas Publishing Corporation, Springfield, IL (1958). 
11. 13 Clark, G. L.: "The Encyclopedia of Microscopy," Rheinhold Publishing Corporation, New York, NY (1961).

11. 14 McCrone, W. C. and J. G. Delly: "I. The Particle Atlas," Edition Two, Ann Arbor Science Publishers, Inc., Ann Arbor, Michigan (1973). 


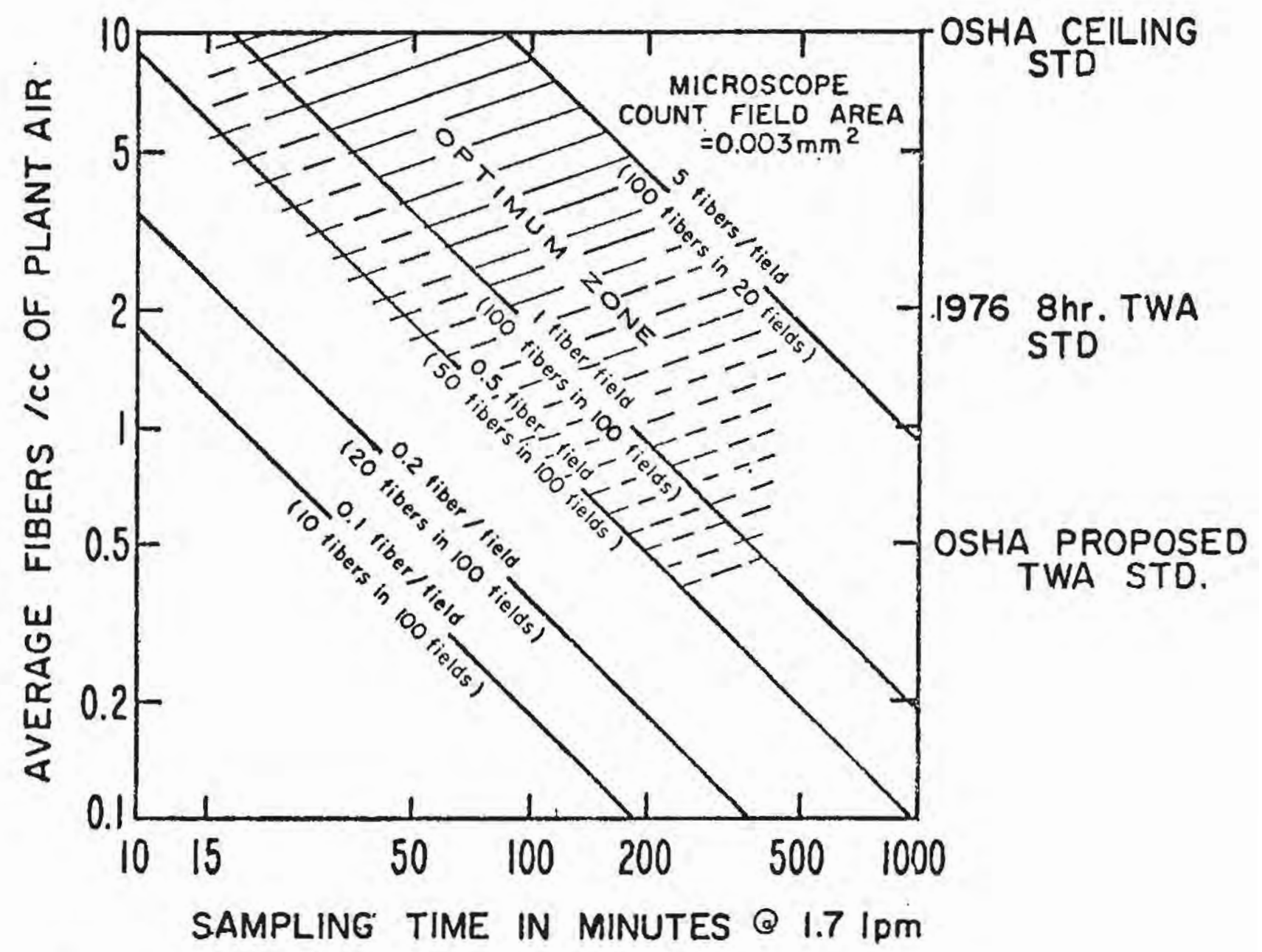

Figure 1. Optimum sampling times for airborne acbestos where microscope field area $=0.003 \mathrm{~mm}^{2}$. 


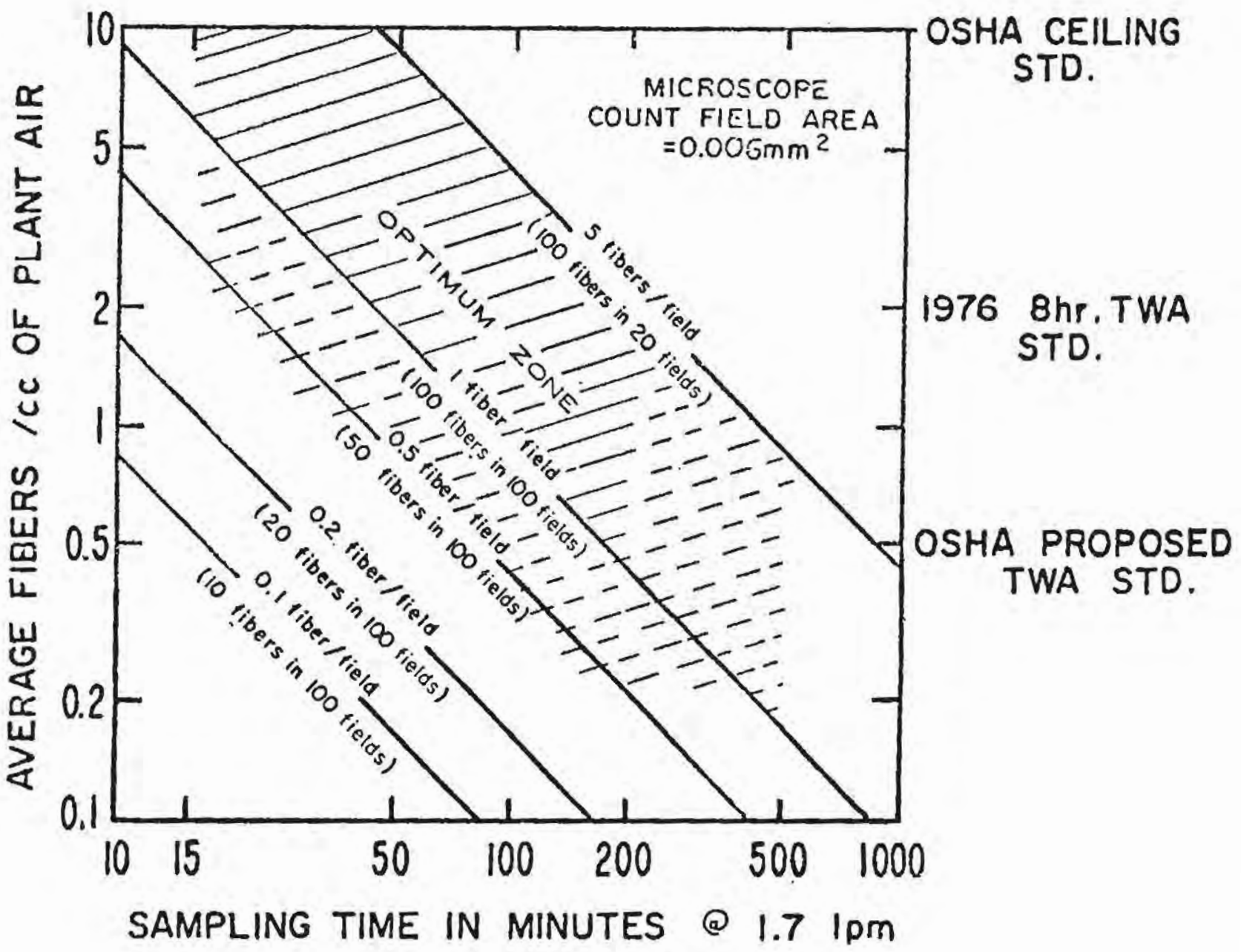

Figure 2. Optimum sampling times for airborne asbestos where microscope field area $=0.006 \mathrm{~mm}^{2}$. 


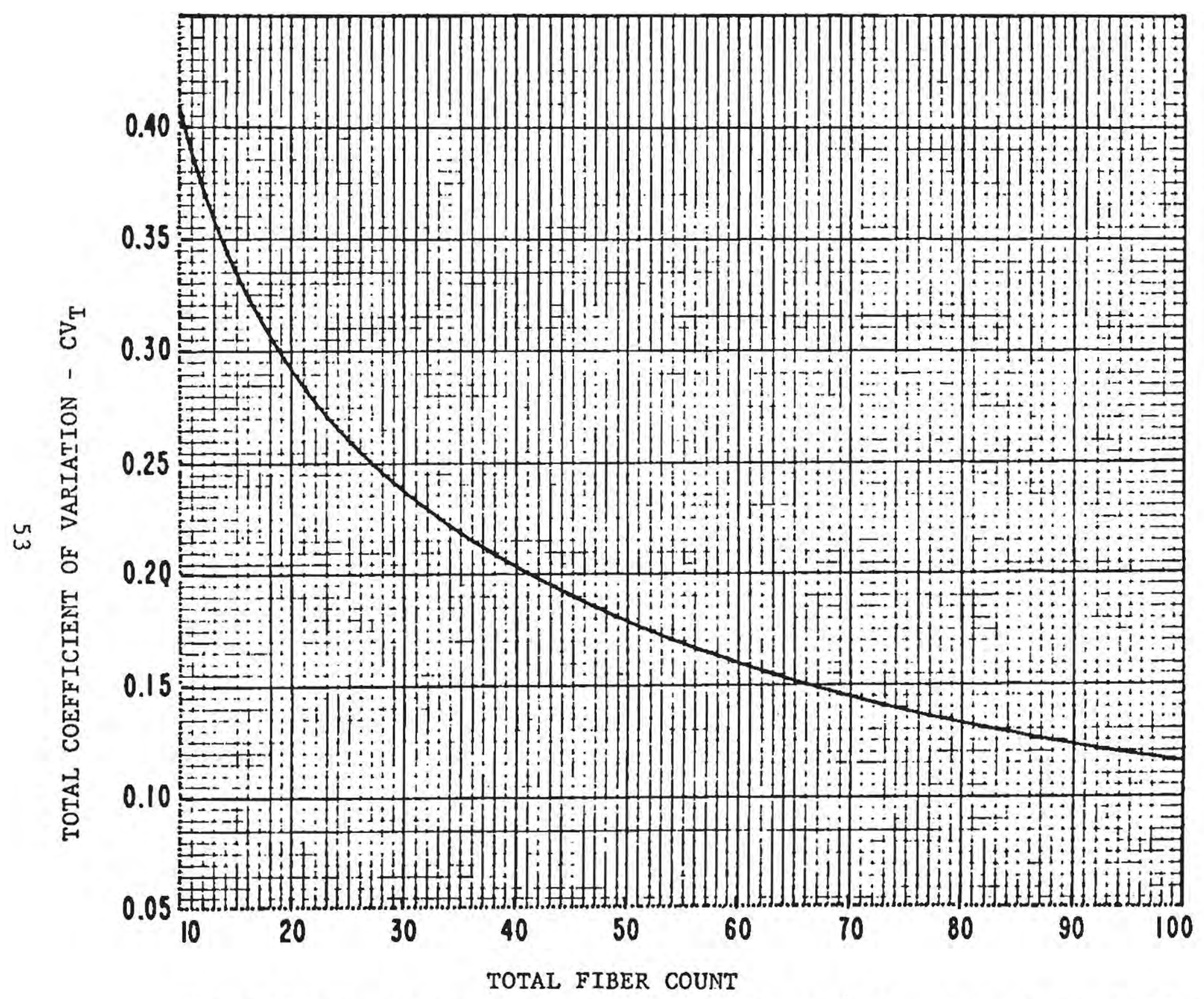

Figure 3 - Total coefficient of varlation as a function of total fiber count (including pump error) 

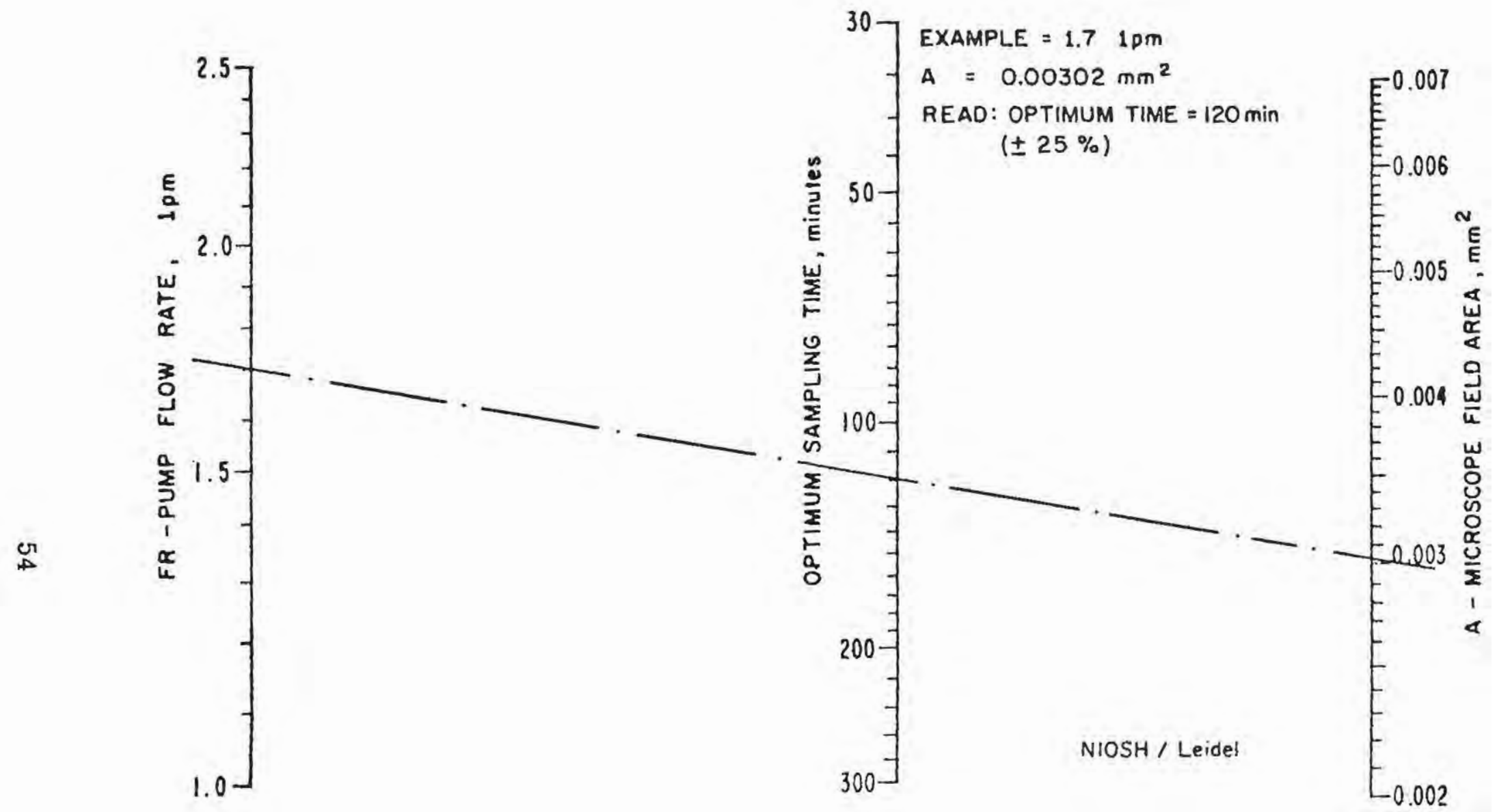

Figure 4. Nomogram of optimum sampling times for airborne asbestos fibers in concentrations of 1 to 10 fibers $/ \mathrm{cm}^{3}$. 


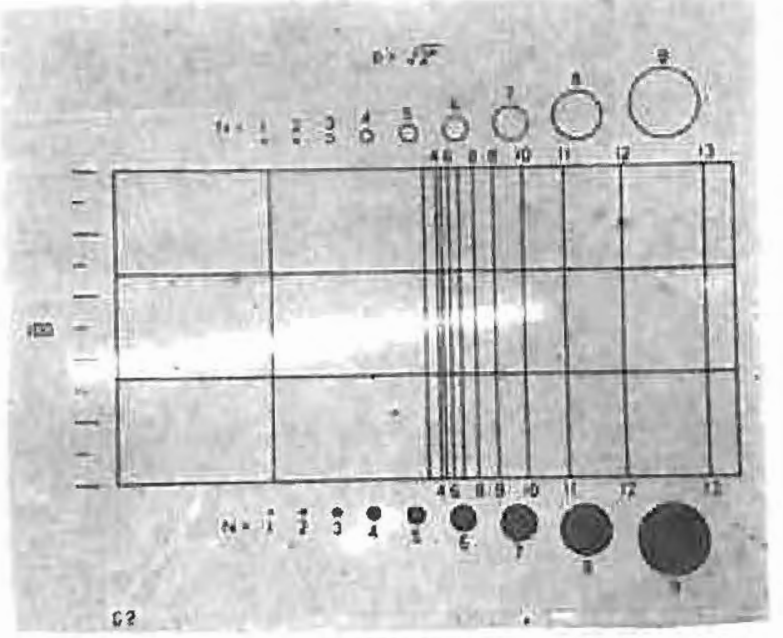

Figure 5. DO NOT COUNT, fiber crosses both left and right sides.

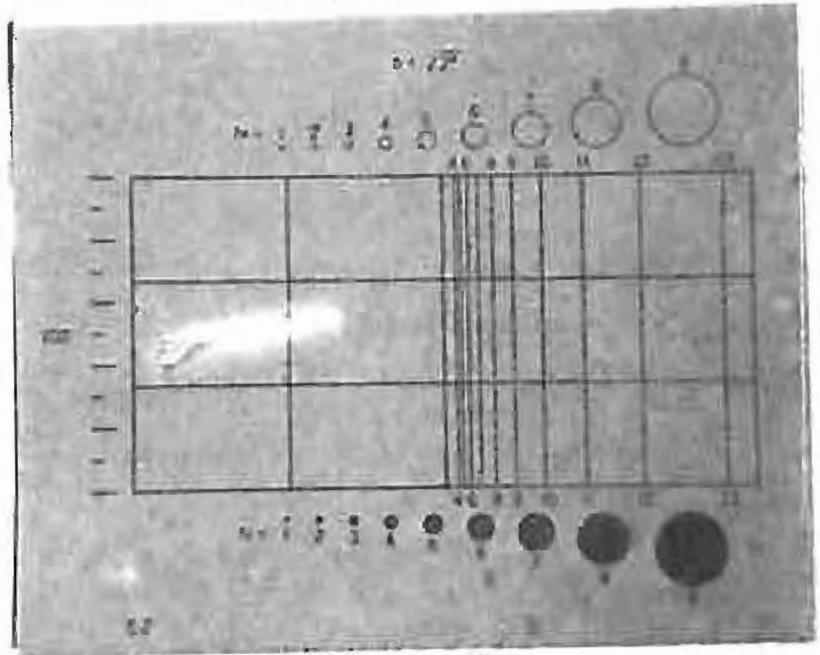

Figure 6. COUNT, as one fiber.

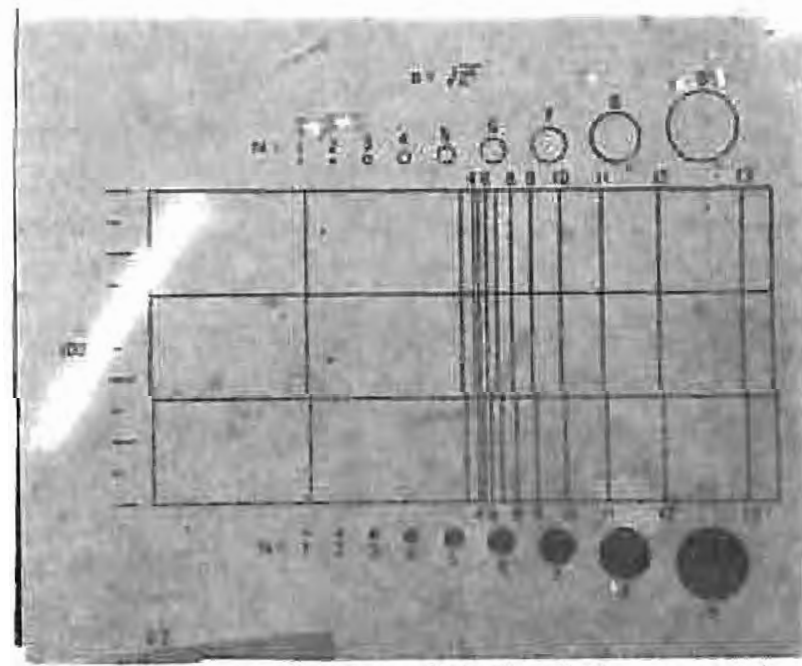

Figure 7. COUNT, as " $1 / 2$ fiber," fiber crosses left side and one end lies within count area.

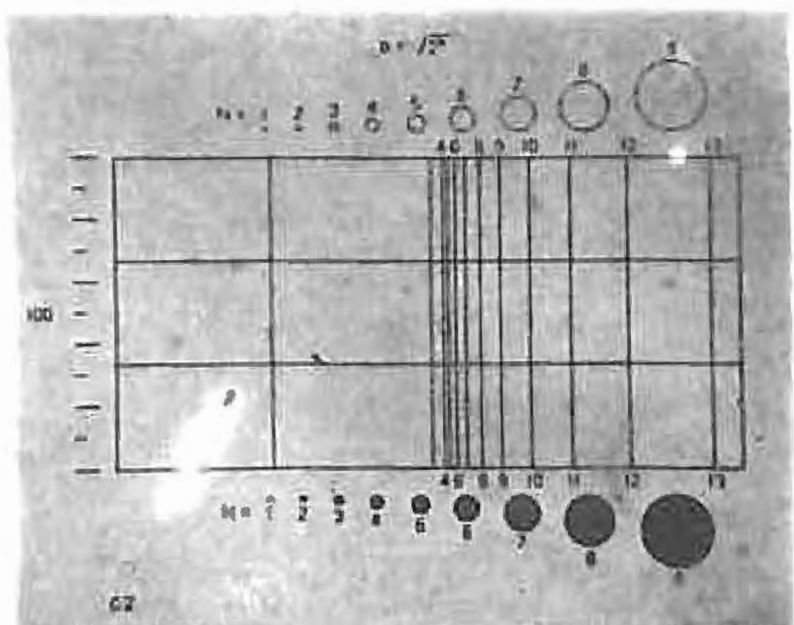

Figure 8. COUNT, as " $1 / 2$ fitser," fiber crosses battom side and one end lies within count area.

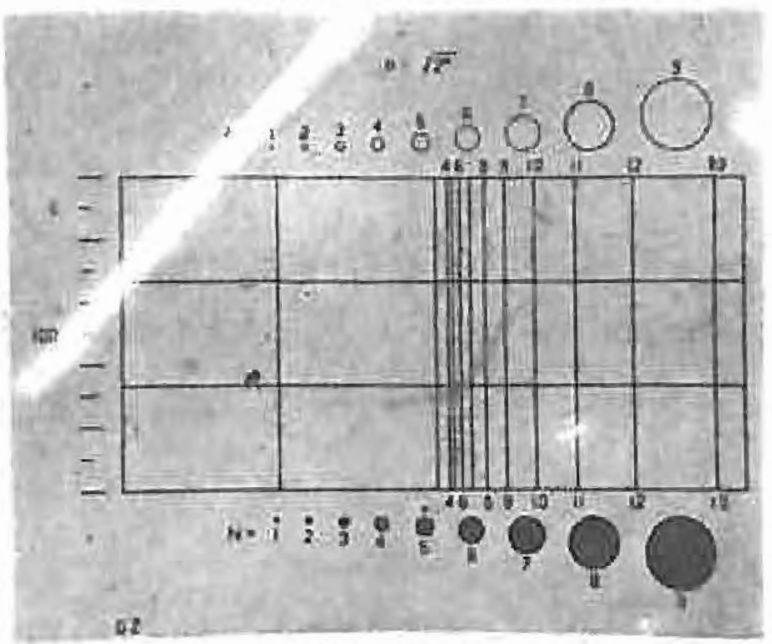

Figure 9. DO NOT COUNT, fiber crosses two sides.

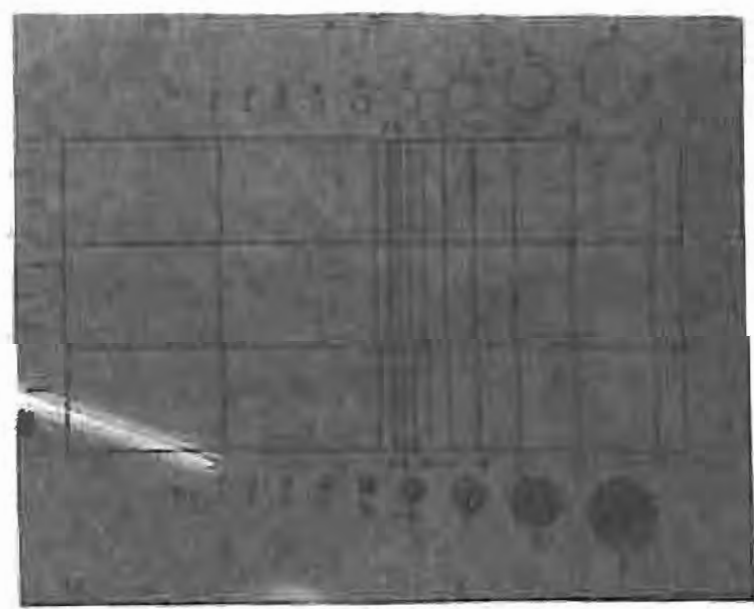

Figure 10. DO NOT COUNT, fiber crosses two sides (bottom left corner). 



\section{APPENDIX B}

AN EVALUATION OF PHASE CONTRAST MICROSCOPES FOR ASBESTOS COUNTING

(This appendix was originally released as NIOSH TR-92

by N. A. Leidel and K. A. Busch in March 1974) 

CONTENTS

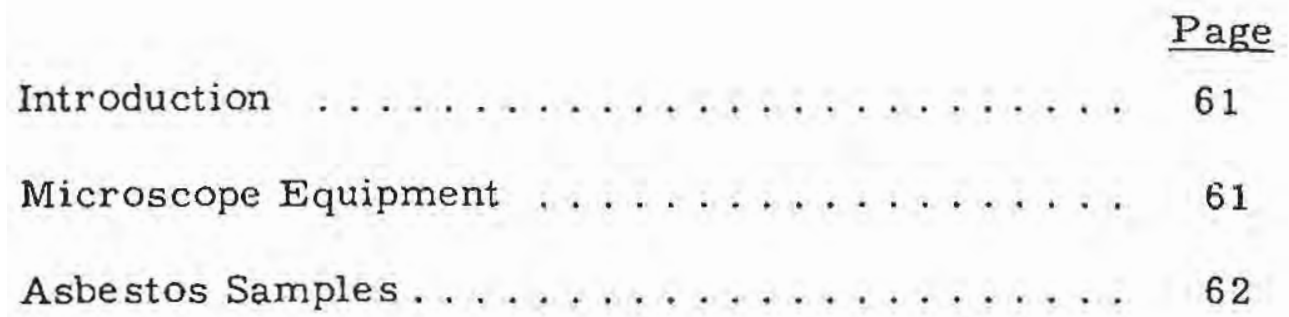

Experimental Design and Test Procedures ...... 62

Statistical Evaluation Procedure ........... 64

Results...................... 65

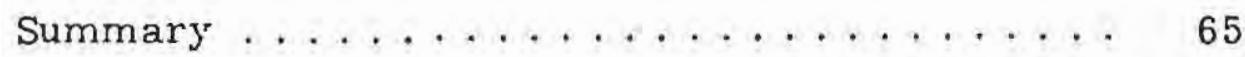

\section{TABLES}

1. Analysis of Variance of $y=\log _{10}$ (fibres/sq. $\mathrm{mm}$ ) 67

2. Results of Duncan's Multiple Range Test of Ratios Among Main-Effect Geometric Means 



\section{INTRODUCTION}

Questions have arisen concerning the comparability of asbestos fiber count results from different makes and models of phase contrast microscopes. The NIOSH Proficiency Analytical Testing (PAT) program has indicated that the most frequent contributors to gross differences in asbestos fiber count results are 1) improperly trained personnel and 2) improperly adjusted equipment. In a few cases though, questions remained concerning the basic performance characteristics of the microscopes. This evaluation study was conducted to see if there was a possibility of gross (greater than 20\%) differences in asbestos fiber count results from counting the same filter on different microscopes by the same personnel. A description of the evaluation procedures and results is contained in this Appendix.

\section{MICROSCOPE EQUIPMENT}

The manufacturer of each phase contrast microscope tested with model and accessory equipment is listed below:

\section{$\underline{\text { Zeiss }}$}

\#KL14B Binocular, Compact B illuminator with iris, 40X 0.65 N. A. Achromat objective, KPL 10X Huygenian eyepieces, IIZ phase condenser

\section{Nikon}

\#SKE Trinocular, 6V30W illuminator, DLL 40X 0.65 N. A. objective, KPL10X Zeiss eyepieces, 77040 phase condenser

Leitz

\#SM-LUX Binocular, 6V5W illuminator, Phaco 402A1 condenser, 40X 0.65 N. A. objective, KPL10X Zeiss eyepieces

\section{Olympus}

\#EH Binocular, $6 \mathrm{~V}$ illuminator, PL $40 \mathrm{X} 0.65 \mathrm{~N}$. A. objective, Zeiss KPL10X eyepieces, phase turret condenser 
Bausch and Lomb

Dynoptic Binocular, PR-27 illuminator, 40X 0.65 Achromat objective, Bausch and Lomb 10X Huygenian eyepieces, phase turret condenser

The above microscopes meet the following equipment specifications as stated in section 6.2 of Appendix A.

1. Microscope body with binocular head.

2. 10X Huygenian eyepieces.

3. Koehler illumination.

4. A Porton reticle.

5. Mechanical stage. Abbe or Zernicke condenser fitted with phase ring (or Heine-type) with a numerical aperture ( $N_{0} A_{0}$ ) equal to or greater than the N.A. of the objective.

6. 40-45X (N. A. 0.65 to 0.75 ) phase contrast achromatic objective.

7. Phase-ring centering telescope or Bertrand lens.

8. Green filter, if recommended by microscope manufacturer.

9. Stage micrometer with $0.01 \mathrm{~mm}$ subdivisions.

\section{ASBESTOS SAMPLES}

The asbestos filters counted were as follows:

\begin{tabular}{ccl} 
Slide\# & Asbestos type & Industry \\
\cline { 2 - 3 } 1 & chrysotile & friction \\
2 & amosite & insulation \\
3 & chrysotile & textile \\
4 & chrysotile & friction \\
5 & chrysotile & cement
\end{tabular}

EXPERIMENTAL DESIGN AND TEST PROCEDURES

Statistical Experimental Design

A $5 \times 5 \times 5$ factorial experiment was performed with three factors: microscope, counter, and slide at the following levels. 


\begin{tabular}{|c|c|}
\hline Microscope & Counter \\
\hline$B \& L$ & A \\
\hline Nikon & B \\
\hline Leitz & C \\
\hline Olympus & D \\
\hline Zeiss & $\mathrm{E}$ \\
\hline
\end{tabular}

Each counter counted each slide using each microscope, resulting in a total of 125 counts. No duplicate counts were performed. Counting was done in random order under the restriction that the five microscopes were always to be in simultaneous use by the five counters. Such random scheduling can be assumed to preclude the possibility that effects of extraneous factors varying systematically during the course of the experiment (e.g., lighting, learning, etc.) could be mistaken for counter or scope differences. Only the experimental error would be inflated by the random presence of such uncontrolled factors and environmental changes.

The five individuals who did the counting for this experiment cannot be considered to be a random sample from any hypothetical population of counters. Therefore, any statistically significant average differences which may have sccurred between counters are not to be used to estimate a variance of systematic counter errors. Instead counter differences should be investigated individually if possible and interpreted in terms of mechanistic causes.

The experimental design specified that enough fields were to be counted to yield approximately 100 total fibers. However, the actual data for the four high-range slides show total counts ranging from 87 to 315 fibers and numbers of fields counted ranging from 20 to 44 . For the low-range slide (\#5), 100 fields were always counted and the total counts range from 6 to 19 fibers.

Counts were expressed in terms of fibers per square millimeter of surface counted. The equation is:

Fibers/sq $\mathrm{mm}=$ (total fibers/number of fields) $/(\mathrm{f})$, where $f=\operatorname{area}(\mathrm{sq} \mathrm{mm}$ ) of one counting field for the microscope used (see below),

\begin{tabular}{lc} 
Microscope & $f(\mathrm{sq} \mathrm{mm} /$ field $)$ \\
\hline B \& L & 0.006084 \\
Nikon & 0.004225 \\
Leitz & 0.007225 \\
Olympus & 0.006724 \\
Zeiss & 0.006806
\end{tabular}


The method of analysis of variance (ANOVA) was used to partition the total variability of the 125 counts into component parts accountable to the following sources of variations.

\begin{tabular}{lc} 
Source of Variation & $\begin{array}{c}\text { Degrees of } \\
\text { Freedom }\end{array}$ \\
\cline { 2 - 2 } Microscopes (M) & 4 \\
Counters (C) & 4 \\
Slides (S) & 4 \\
M x C Interaction & 16 \\
M x S Interaction & 16 \\
C x S Interaction & 16 \\
M x C x S Interaction $\quad$ (used as an estimate of & \\
$\quad$ experimental error) & \\
\hline Total &
\end{tabular}

F-ratios were used as the statistical criteria to test significance of each source of variation. Decisions were made at the 0.05 type-1 error level.

Since results (fibers/sq $\mathrm{mm}$ ) ranged from 327 to 2935 for slides $1,2,3$, and 4 , but only from 8.9 to 30.8 for slide $\# 5$, it was clear that variability of results among counters and scopes was roughly proportional to mean fiber concentrations. Therefore, the response variable for use in the analysis of variance was taken to be:

$$
y=\log _{10}(\text { fibers } / \text { sq } \mathrm{mm} \text { ). }
$$

Such a $\log _{10}$-transformation was used to minimize interactions over the wide range of concentrations of the five slides. If no transformation had been used, it would have been necessary to perform a separate statistical analysis on each slide.

The wide range of counts on different filters also creates the problem that the standard deviation of $y$-values for filter 5 is much higher than the standard deviations for filters 1, 2, 3, and 4. The theoretical (Poisson-derived) variance of true y-valucs (calculated from true counts in different areas of the same filter) is equal to the reciprocal of the average number of fibers counted. Since considerably fewer total fibers were counted for filter 5 than for filters $1,2,3$, and 4 , the assumption of homogeneity of variance (which is required in order for the method of analysis of variance to be strictly valid) is not true with respect to the F-test of overall filter means. However, the 
invalid F-test for filter means does not concern us because filter means are known to be unequal. F-tests of counter means or of microscope means are valid becausc each mean has approximately the same standard error, namely

$$
\begin{gathered}
\text { S.E. }(\text { mean })=\left(\sigma^{2} / 25\right)^{1 / 2} \text {, where } \\
\sigma^{2}=(1 / 5)[(1 / 857)+(1 / 1006)+(1 / 822)+(1 / 1537)+(1 / 19)]=0.0113
\end{gathered}
$$

The variance $\sigma^{2}=0.0113$ is the theoretical (Poisson-derived) error variance of the $y$-transform, but in the analysis of variance an empirical estimate was calculated from the data to allow for the possibility that additional (nonPoisson) sources of variation had inflated the experimental error (e.g. , clumping of fibers, uneven film thickness, or other cause for non-uniform distribution over the surfaces of slides).

\section{RESULTS}

The results of the analysis of variance are shown in Table 1 . The main effects of both microscopes and counters were highly significant and, of course, a significant main "effect" was also expected for slides. None of the interactions approached statistical significance because, on the scale of the $\log _{10}$-transformation, approximately equal differences among scopes and among counters were obtained, respectively, for all five slides. This implies that systematic factor effects tended to be equal for all five slides when expressed as percentages of respective mean counts. In fact, there was an almost complete absence of interactions in this experiment as indicated by the size of the pooled variance for the four interaction effects which was equal to 0.0095 . This value agrees almost exactly with the expected theoretical (Poisson) variance of 0.0113 derived earlier in this report.

The final step in the statistical analysis was to elucidate the pattern of differences among the five levels of each main effect. This was done by using Duncan's Multiple Range Test to perform multiple pairwise comparisons among main effect means. Results are shown in Table 2 which indicate that: 1) the Nikon microscope produced significantly higher counts than the other four scopes which were statistically homogeneous among themselves, and 2) one counter had significantly lower results and one counter had significantly higher results compared to the remaining three counters whose results were statistically homogeneous among themselves,

\section{SUMMARY}

The following observations about scope differences and counter differences apply to each of the five slides. NOTE: These observations cannot be used as a basis for a general evaluation of the quality of a particular make or model microscope since only one instrument from each manufacturer was used in this study. 
1. For each of the five counters, the Nikon microscope tested produced counts which were approximately $45 \%$ higher on the average than counts obtained using the particular Leitz, Zeiss, Olympus, or B \& L microscopes in the evaluation.

2. The excellent agreement between the empirical error variance, calculated from pooled interaction effects, and the theoretical error variance, based upon the assumption of Poisson-distributed true counts, indicated that each filter had been sampled such that excessive variability among fields in different areas of a slide did not exist. That is, results indicate that film thickness was uniform and that clumping of fibers (non-random coalescence) did not occur.

3. Using any of the five scopes, three counters had statistically homogeneous counts: B, C, and D. Taking the average of the se three counters as $100 \%$, counter $A^{\prime}$ 's average was $84 \%$ ( $16 \%$ lower) and counter $E^{\prime}$ 's average was $127 \%$ ( $27 \%$ higher).

4. The evaluation study has shown that a significant difference in asbestos fiber counts can result when the same filters are counted on different makes and models of microscopes. Significant differences can also exist between trained counters.

5. It cannot be concluded that all Nikon phase contrast microscopes will consistently yield asbestos fiber counts $45 \%$ higher than counts done on other microscopes or that the other four makes of scopes will yield consistently equal counts. A much more extensive study would be required to answer the se questions.

6. The authors believe that any laboratory counting asbestos on membrane filters should be part of an interlaboratory collaborative quality program where asbestos filters are exchanged between laboratories. This participation would insure that 1) equipment is properly adjusted and calibrated, 2) counters are properly trained and their counting proficiency is continually evaluated, and 3) comparable results are obtained from each laboratory. Of the counters who participated in this study, only one was a participant in an interlaboratory collaborative quality control program. This type of program is now being conducted by the National Institute for Occupational Safety and Health (NIOSH) for both governmental and private laboratories. 
Table 1. Analysis of Variance of $y=\log _{10}$ (fibres $/ \mathrm{sq} \cdot \mathrm{mm}$ )

\section{Degrees of}

Source of Variation Freedom

Variance

F-Ratio Probability

\begin{tabular}{|c|c|c|c|c|c|c|}
\hline Microscopes (M) & 4 & & 0,1320 & & 13.2 & $<10^{-7}\left(*^{2}+4\right)$ \\
\hline Counters (C) & 4 & & 0.1098 & & 11.0 & 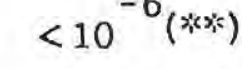 \\
\hline Slides (S) & 4 & & 15.3681 & & 1537. & -- \\
\hline$M \times C$ & 16 & & 0.0056 & & 0.56 & $0.90(\mathrm{NS})$ \\
\hline$M \times S$ & 16 & 112 & 0.0055 & 0.0095 & 0.55 & 0.91 (NS) \\
\hline$C \times S$ & 16 & & 0.0153 & & 1. 53 & 0.12 (NS) \\
\hline $\mathrm{M} \times \mathrm{C} \times \mathrm{S}$ (Error) & 64 & & 0.0100 & & & \\
\hline Total & 124 & & & & & \\
\hline
\end{tabular}

Table 2. Results of Duncan's Multiple Range Test of Ratios Among Main-Effect Geometric Means

\begin{tabular}{|c|c|c|c|c|c|}
\hline \multirow{2}{*}{$\frac{\text { Microscope }}{\text { Leitz }}$} & \multicolumn{2}{|c|}{$\begin{array}{l}\text { Geometric Mean } \\
(\% \text { of Grand Mean) }\end{array}$} & \multirow{2}{*}{$\frac{\text { Counter }}{\text { A }}$} & \multicolumn{2}{|c|}{$\begin{array}{l}\text { Geometric Mean } \\
(\% \text { of Grand Mean) }\end{array}$} \\
\hline & 90.31 & \multirow{5}{*}{$\begin{array}{l}\text { Geom. Mean } \\
=92.8 \%\end{array}$} & & 82.8 & \multirow{5}{*}{$\begin{array}{l}\text { Geom. Mean } \\
=98.7 \%\end{array}$} \\
\hline Zeiss & 92.5 & & B & 94.5 & \\
\hline Olympus & 93.2 & & $\mathrm{C}$ & 97.7 & \\
\hline B \& L & 95.5 & & $\mathrm{D}$ & 104.1 & \\
\hline Nikon & 134.6 & & $\mathrm{E}$ & 125.7 & \\
\hline \multicolumn{6}{|c|}{$\begin{array}{l}\text { Values within a bracket do not differ significantly at the } 0.05 \\
\text { probability level. }\end{array}$} \\
\hline
\end{tabular}





\title{
APPENDIX C
}

\section{UNBIASED ESTIMATES OF COEFFICIENTS OF VARLATION FOR} ASBESTOS COUNTING DETERMINED FROM JOHNS-MANVILLE DATA

\author{
Kenneth A. Busch \\ Nelson A. Leidel \\ Richard W. Hornung \\ Randall J. Smith
}

This Appendix was originally presented at the Society for Occupational Environmental Health Conference "Occupational Exposures to Fibrous and Particulate Dust and Their Extension Into the Environment," Washington, D.C. (December 1977). 



\section{UNBIASED ESTIMATES OF COEFFICIENTS OF VARIATION FOR ASBESTOS COUNTING DETERMINED FROM JOHNS-MANVILLE DATA}

\section{INTRODUCTION}

Counts of asbestos fibers in samples of contaminated air are subject to random variations of several types. The variance components for asbestos counting done by NIOSH Analytical Method No. 239 (1) are discussed in detail in draft papers by Leidel and Busch (2) and by Leidel, Bayer, Zumwalde and Busch (3). In these papers, the variability is expressed as a coefficient of variation $(\mathrm{CV}=$ standard deviation $\div$ mean). The $\mathrm{CV}$ for determinations of asbestos fiber concentrations has been shown to decline with increasing average total numbers of fibers counted. An irreducible base $\mathrm{CV}$ is due to count variations caused by random locational variations of fibers on the surface of the filter. Assuming that:

1. each fiber in the air to be sampled is equally likely to terminate, after the sample is taken, on any one of the fields of the filter, and

2. the concentration of fibers/field is low,

suggests that the total number of fibers counted per wedge follows (approximately) a Poisson distribution (4). These assumptions amount to assuming that the fibers are in low concentration and have no "social instincts," i.e., no tendency to congregate or clump on localized parts of the filter. This basic Poisson component of the counting error has a CV equal to the reciprocal of the square root of the average total number of fibers counted. Thus, for an average of 100 fibers counted, the base CV would be $1 / \sqrt{100}=0.10$ (i.e., $10 \%$ ).

In this paper, NIOSH presents its derivation of an empirical equation for the relationship between the CV and total fiber count. The equation is fitted to CV's determined from data collected by Johns-Manville in an in-house interlaboratory study (5) of the NIOSH asbestos count method. The mathematical model for this equation was chosen to be consistent with the above-mentioned base CV due to Poisson distribution of fibers over counting areas on the surface of the filter. The equation was fitted to 109 estimates of the CV for asbestos counting from 109 filters. Each filter was counted by two to five counters located in five J-M laboratories, each of whom prepared his own wedge for counting. A total of 15 counters participated in the study, none of whom counted a given filter more than once. From 6 to 10 different filters were counted by the various counters. The resulting CV's for fiber counting (denoted by $\mathrm{CV}_{\mathrm{F}}$ ) included random intrafilter variations and intercounter variations but did not include random pump flow rate variations. The latter relative variance component was added in mathematically to obtain the total coefficient of variation for the net error due to sampling and analysis. The relationship is

$$
\mathrm{CV}_{\mathrm{T}}=\sqrt{\mathrm{CV}_{\mathrm{F}}^{2}+\mathrm{CV}_{\mathrm{P}}^{2}} \text {. }
$$

where $\mathrm{CV}_{\mathrm{F}}$ is the coefficient of variation for fiber counting and $\mathrm{CV}_{\mathrm{P}}$ is assumed to be 0.05 (i.e. $5 \%$ ) based on a previous estimate of the coefficient of variation for random pump flow rate variations. 
These $\mathrm{CV}_{\mathrm{T}}$ estimates from the J-M data included all the random sources of variation that we have stated that NIOSH should consider. These are intra-filter variations (interfield within a wedge and interwedge within a filter), random intercounter variations and random pump flow rate variations. This definition of the $\mathrm{CV}_{\mathrm{T}}$ is consistent with other NIOSH exposure monitoring methods.

An initial estimate of $\mathrm{CV}_{\mathrm{F}}$ was taken to be the ratio estimate $\mathbf{s} / \overline{\mathbf{x}}$, where $\mathrm{s}$ is a sample standard deviation for a set of $n$ fiber counts made by $n$ different counters from the same plant on different wedges taken from the same filter, and $\bar{x}$ is the average total number of fibers counted. However, since sample sizes for the $s / \bar{x}$ estimates of $C_{F}$ 's were small, ranging from $n=2$ to $n=5$, the estimates are generally biased. Assuming that replicate fiber concentration estimates follow a normal distribution with mean $\mu$ and standard deviation $\sigma$, bias in $\mathrm{s} / \overline{\mathrm{x}}$ (as an estimate of $\mathrm{CV}_{\mathrm{F}}$ $=\sigma / \mu)$ can be assumed because, for a normal distribution, the following relationships hold (6):

$$
\begin{aligned}
& \mathrm{E}(\mathrm{s} / \overline{\mathrm{x}})=\mathrm{E}(\mathrm{s}) \mathrm{E}(1 / \bar{x}), \\
& \mathrm{E}(\mathrm{s}) \leq \sigma, \text { and } \\
& \mathrm{E}(1 / \overline{\mathrm{x}}) \geq 1 / \mu .
\end{aligned}
$$

The notation $\mathrm{E}($ ) denotes the expected value (average) of the variable in parentheses. The biases in the two terms of the product would not cancel each other in general, so that bias in $\mathrm{s} / \overline{\mathrm{x}}$ must be assumed to exist. Therefore, it was decided to correct each $\mathrm{CV}_{\mathrm{F}}$ estimate for bias before fitting a regression curve to the spectrum of $\mathrm{CV}_{\mathrm{F}}$ estimates against corresponding average total fiber counts, $\bar{x}$. If such a curve were fitted directly to the $s / \bar{x}$ biased estimates, it would be difficult to ascertain the net bias in the curve because it would be a highly complex function of small biases in the many individual $\mathrm{s} / \overline{\mathrm{x}}$ estimates. We have attempted to develop an estimation procedure for an unbiased empirical approximation to the true $C_{\mathrm{F}}$ vs. $\overline{\mathrm{x}}$ curve. The objective was to use the resulting curve to obtain more accurate estimates of $\mathrm{CV}_{\mathrm{F}}$ (and corresponding $\mathrm{CV}_{\mathrm{T}}$ ) than were given by the highly variable (and biased) individual ratio estimates $\mathrm{s} / \overline{\mathrm{x}}$. The methods used to develop the desired $\mathrm{CV}_{\mathrm{T}}$ vs. $\overline{\mathrm{x}}$ curve are discussed below.

Table \#1 shows the relationship between the fiber density (fibers per field) on the wedge and the stopping point for the NIOSH method. The stopping point, either a fixed number of fields or a fixed total number of fibers counted, is shown in parentheses. Only the "fixed fields" stopping rule was investigated for this report - it applies when fiber densities are either low (0.1 to 1.0 fibers/field) or high ( $>5$ fibers/field). In the latter case, the NIOSH procedure requires counting at least 20 fields (hence more than 100 fibers).

For fiber densities between 1 and 5 fibers/field, the NIOSH counting procedure requires that enough fields be counted to yield a total fiber count of 100 . Under this "fixed fibers" stopping rule, variability occurs in the denominator of the fibers/field ratio and a different statistical distribution would exist than for the "fixed fields" stopping rule (where variability occurs in the numerator). Work is still in progress to develop the required statistical theory for unbiased estimation of $\mathrm{CV}_{\mathrm{T}}$ when the stopping rule is a total fiber count of 100 .

\section{STATISTICAL PROTOCOL FOR ESTIMATION OF $\mathrm{CV}_{\mathrm{T}}$ AS A FUNCTION OF $\overline{\mathrm{x}}$}

Exact formulas for an unbiased estimate could not be derived mathematically because of intraactability of the required integrals. Therefore, approximations to the estimation equations were obtained empirically through Monte Carlo simulation using a high speed computer. The general procedure is given below in nine steps. Steps $5-8$ are an iterative loop but steps $1-4$ and step 9 are done only once. 
Step 1. For a given true $\mathrm{CV}_{\mathrm{F}}, 2000$ random samples of size $\mathrm{n}$ were taken from a normal distribution. For each sample the initial $\mathrm{CV}_{\mathrm{F}}$ estimate, $\mathrm{c}=\mathrm{s} / \overline{\mathrm{x}}$ was computed, and a histogram was formed of the 2000 estimates. The mean $(\mathrm{c})$, standard deviation $\left(\mathrm{s}_{\mathrm{c}}\right)$, third moment $\left(\mathrm{m}_{3 \mathrm{c}}\right)$, and coefficient of skewmess $\left(\beta_{1 \mathrm{c}}=\mathrm{m}_{3 \mathrm{c}} / \mathrm{s}_{\mathrm{c}}^{3}\right)$ were also calculated. This was repeated for the 28 combinations of the following $n$ and $C V_{F}$ values: $n=2,3,4,5$ and $\mathrm{CV}_{\mathrm{F}}=.15, .20, .25, .30, .35, .40, .45$.

Step 2. Since it was apparent that many of the distributions of $c$ or $\log c$ values were highly skewed (particularly for $n=2$ ) different transformations of $c$ were tried until one was found which had near-zero $\beta_{1}$ 's and symmetrical-looking (i.e. "normal"'-looking) histograms. The transformation which was the best compromise for all 28 cases was $y=$ $\log _{10}(c+0.12)$. Figures 5 and 6 show examples of histograms of $c, \log c$, and $\log _{10}(c+0.12)$ for $n=2($ Figure 5$)$ and $n=5$ (Figure 6$)$. The six histograms shown all are for $\sigma / \mu=0.2$.

Step 3. Bias ratios ( $k$ ) were calculated for each of the 28 points, where

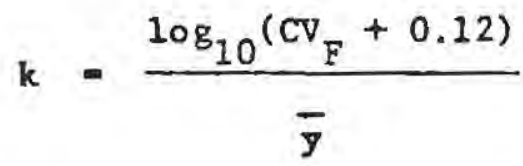

For each sample size $n$, the seven $\mathrm{k}$ values were plotted against $\log \left(\mathrm{CV}_{\mathrm{F}}+0.12\right)$ and each plot was smoothed with a third degree polynomial. The resulting four curves for $\mathrm{n}=2,3,4,5$ are shown in Figure 4. An example of one of the equations is given below for $\mathrm{n}=3$.

$$
\begin{aligned}
k= & 0.8594+0.8584 \log _{10}\left(C \nabla_{F}+0.12\right)+3.5319 \log _{10}^{2}\left(C V_{F}+0.12\right) \\
& +3.2106 \log _{10}^{3}\left(C V_{F}+0.12\right)
\end{aligned}
$$

Step 4. The k-equations from Step 3 were used to correct the observed c's for bias by multiplying each value $y_{i}$ by $k_{i}$ (see Step 5 ), where $i=1,2, \ldots, 109$ is an index denoting the 109 points.

Step 5. An iterative weighted least squares regression procedure was used to fit a quadratic equation to values of $\mathrm{k}_{\mathrm{i}} \mathrm{y}_{\mathrm{i}}$ (dependent variable) vs. $\mathrm{x}_{\mathrm{i}}$ (independent variable). The equation has the form:

$$
k_{1} y_{1}^{\prime}=a_{0}+a_{1} \log x_{1}+a_{2} \log ^{2} x_{1}
$$

where $\mathrm{k}_{\mathrm{i}} \mathrm{y}_{\mathrm{i}}^{\prime}$ denotes the predicted value of $\log _{10}\left(\mathrm{CV}_{\mathrm{Fi}}+0.12\right)$ for each of the 109 points; $\mathrm{a}_{0}, \mathrm{a}_{1}$, and $\mathrm{a}_{2}$ are numerical regression coefficients; $\mathrm{x}_{\mathrm{i}}$ is the $\mathrm{i}^{\text {th }}$ total fiber count; and $\mathrm{CV}_{\mathrm{Fi}}$ is the corresponding $\mathrm{i}^{\text {th }}$ predicted $\mathrm{CV}_{\mathrm{F}}$ value. 
Step 6. For each iteration, $\mathrm{k}_{\mathrm{i}}$ was recalculated from the appropriate third degree polynomial in Step 3 as a function of the $\mathrm{k}_{\mathrm{i}} \mathrm{y}_{\mathrm{i}}^{\prime}$ estimate of $\log \left(\mathrm{CV}_{\mathrm{Fi}}+0.12\right)$ from the previous (Step 5) iteration.

Step 7. The weighting function $\left(w_{i}\right)$ for the $i^{\text {th }}$ point in fitting the regression line of Step (5) was the reciprocal of the variance of $k_{i} y_{i}$ which is:

$$
w_{1}=\left\{\frac{k_{1}^{2} c v_{F 1}^{2}}{\left(C v_{F 1}+0.12\right)^{2}}\left[\frac{1}{2\left(n_{1}-1\right)}+\frac{c v_{F 1}^{2}}{n_{1}}\right]\right\}^{-1}
$$

Step 8. Steps 5-7 were repeated iteratively until the maximum deviation between successive fitted values, $\mathrm{k}_{\mathrm{i}} \mathrm{y}_{\mathrm{i}}$, differed by no more than 0.004 . This corresponds to a fitting error in $\mathrm{CV}_{\mathrm{F}}$ of no more than 0.001 .

Step 9. The resulting equation was then detransformed to yield:

$$
C V_{F}^{\prime}=10^{a_{0}+a_{1} \log x+a_{2} 10 g^{2} x}-0.12
$$

where $\mathrm{CV}_{\mathrm{F}}$ denotes the estimated value of $\mathrm{CV}_{\mathrm{F}}$ determined from an arbitrary total fiber count $x$. Finally, the estimated $\mathrm{CV}_{\mathrm{T}}$ (denoted $\mathrm{CV}_{\mathrm{T}}^{\prime}$ ) was calculated by adding in $\mathrm{CV}_{\mathrm{P}}=.05$ for the pump error component:

$$
C V_{T}^{\prime}=\sqrt{\left(C V_{F}^{\prime}\right)^{2}+(0.05)^{2}}
$$

Note that, since $C V_{F}^{\prime}$ exceeds the assumed value $C V_{P}=.05$ considerably, any value for $C_{P}$ in the range .03 to .06 would yield nearly equal values of $\mathrm{CV}_{\mathrm{T}}$.

\section{RESULTS}

The fitted quadratic curve is shown in Figure 2 and has the equation:

$$
\log \left(C V_{F}^{\prime}+0.12\right)=0.0595-0.3241 \log x-0.01585 \log ^{2} x .
$$

The corresponding detransformed curve is shown in Figure 3. Its equation is:

$$
C V_{T}^{\prime}=\sqrt{\left(C V_{F}^{\prime}\right)^{2}+(0.05)^{2}}
$$

where $\mathrm{CV}_{\mathrm{F}}^{\prime}=10^{\left(0.0595-0.3241 \log \mathrm{x}-0.01585 \log ^{2} \mathrm{x}\right)}-0.12$. 
The equation is graphed int Figure 3 and shows predicted $C V_{\mathrm{T}}$ 's ranging from 0.41 (for 10 fibers counted in 100 fields) to 0.11 (for 100 fibers counted in 100 fields). Table 2 lists predicted $\mathrm{CV}_{\mathrm{T}}$ 's for various fiber densities and stopping rules. The stopping point, either fixed number of fields or a fixed total number of fibers counted, is shown in parentheses.

The counting rules to which the $\mathrm{CV}_{\mathrm{T}}$ 's of Figure 3 are applicable are repeated below for emphasis. Figure 3 applies to counting to a constant number of fields. Thus, it applies both to: 1) the case of low fiber densities ( 0.1 to 1.0 fibers/field), in which case 100 fields are counted, and to 2 ) the case of high fiber densities ( $>5$ fibers/field), in which case 20 fields are counted.

Figure 3 does not apply when fiber densities are between 1 and 5 fibers/field. In this range the NIOSH counting procedure requires that enough fields be counted to yield a total fiber count of 100. Since variability is in the denominator instead of the numerator for this "fixed fibers" stopping rule, a different statistical distribution of c-values would exist than that used to develop Figure 3 (the "fixed fields" stopping rule). Work is in progress to develop the required statistical theory for unbiased estimation of $\mathrm{CV}_{\mathrm{T}}$ when the stopping rule is a total fiber count of 100 .

\section{CONCLUSIONS}

Figure 3 generally gives lower $\mathrm{CV}_{\mathrm{T}}$ estimates compared to an earlier (biased) curve presented in the NIOSH Manual of Analytical Methods (1). The new transformation, $y=\log _{10}(c+0.12)$, removes negative skewness which existed in the sampling distribution of the earlier transformation, $\log c$, so that the least squares fitting procedure now produces least squares estimates (i.e. mean values) corresponding to the center point (50th percentile) rather than a lower percentile. The correction for bias provided in Figure 4 also serves to increase $\mathrm{CV}_{\mathrm{F}}^{3}$. However, the reason that the new curve shows lower $\mathrm{CV}_{\mathrm{T}}$ 's is that the earlier curve was fitted to partially incorrect raw data. Some of the $s / \bar{x}$ estimates of $\mathrm{CV}_{\mathrm{F}}$ were calculated directly from groups of counts with no adjustment for variable numbers of fields counted. These CV's were biased upwards and have now been deleted. The overriding error occurred in the computer program - a portion of the weighting function was coded as $\left(1+2 \log ^{2} C V_{T}\right)^{-1 / 2}$ instead of $\left(1+2 C_{T}^{2}\right)^{-1 / 2}$. This programming error caused the weights to be ordered in the wrong direction against $\mathrm{CV}_{\mathrm{T}}$ and had the effect of causing a fairly large upward bias in the fitted $\mathrm{CV}_{\mathrm{T}}$ curve. In fact, some predicted $\mathrm{CV}_{\mathrm{T}}$ 's were more than $50 \%$ too high.

The revised curve given in this paper indicates that the NIOSH-recommended asbestos sampling and couriting procedure is capable of providing fiber concentration estimates within about $23 \%$ $(1.96 \times 0.114 \times 100 \%)$ of the true concentration $95 \%$ of the time when the fiber density on the plate is high (above 1 fiber per field) and a fixed number of fields are counted to yield a total fiber count of 100 or more. ( $\mathrm{CV}_{\mathrm{T}}=0.114$ is the value from Figure 3 for a total fiber count of 100.) When fiber densities are below 1 fiber/field, a maximum of 100 fields will be counted but the total fiber count will be below 100 . In this case, $C V_{T}$ can be as high as 0.41 when only 10 fibers are counted in 100 fields. Indications are that the "100 fibers" stopping rule yields a $C_{\mathrm{T}}$ similar to that for the " 100 fields" stopping rule when 100 fibers are counted. However, this value must be verified through development of additional statistical theory.

Obvious practical ramifications of the sampling strategy are implied by relationships shown in Table 2 and Figure 3 between $\mathrm{CV}_{\mathrm{T}}$ and the fibers/field counted. One should take as long a sample as necessary to get sufficient surface fiber density on the filter so that the resulting average number of fibers per field counted is close to 1 . Samples yielding even higher surface densities (in the range of 6 to 7 fibers/field counted) would probably give as good or better precision but above this range the inability to distinguish some individual fibers would probably cause both a bias in the count and increased $\mathrm{CV}_{\mathrm{T}}$. Since replicate counts were not available in this higher range, we could not determine an upper limit for the fiber concentration which could be counted precisely and accurately. 


\section{ACKNOWLEDGEMENT}

The difficult implementation of the iterative weighted least squares estimation procedure developed in this study, as well as the Monte Carlo sampling procedures needed to determine statistical distributions of transformations, could not have been done without special programs written for a high speed computer by Mr. Alfred R. Saylor of Statistical Services Branch. We also wish to express our gratitude to Mrs. Patricia J. Zehnder for her assistance in organizing and typing this manuscript.

\section{REFEREN `ES}

1. Taylor, D. G. 1977. NIOSH Manual of Analytical Methods. 2nd Edition, Vol. 1, P\&CAM No. 239.

2. Leidel, N. A. and Busch, K. A. June, 1977. Treatment of Random and Systematic Errors When Monitoring for Asbestos. NIOSH in-house working draft, Cincinnati, Ohio 45226.

3. Leidel, N. A., Bayer, S. G., Zumwalde, R. D., and Busch, K. A. September, 1977. USPHS/NIOSH Membrane Filter Method for Evaluating Airborne Asbestos Fibers. NIOSH in-house working draft, Cincinnati, Ohio 45226.

4. Mood, A. M. 1950. Introduction to the Theory of Statistics. 3.5 The Poisson Distribution. McGraw-Hill Book Company, Inc., New York, pp. 59-61.

5. Comments of Johns-Manville with Respect to the Notice of Proposed Rulemaking: Occupational Exposure to Asbestos, Federal Register, October 9, 1975. Submitted to the Public Record at the U.S. Department of Labor, Occupational Safety and Health Administration, Washington, D.C., April, 1976.

6. Johnson, N. L. and Kotz, S. 1970. Continuous Univariate Distributions. Ch. 13. Normal Distributions. Section 4 Characterizations. John Wiley \& Sons, Inc., New York, Vol. 1, p. 50. 
Table 1

Relationship Between F1ber Density and Stopping Rule for the NIOSE Method

Fibers/Field

0.1

0.2

0.5

1

1

2

5.

6

$\geq 7$
Fibers

10

20

50

100

(100)

(100)

(100)

120

$\geq 140$
Flelds

(100)

(100)

(100)

(100)

100

50

20

(20)

(20) 
Table 2

Predicted $\mathrm{CV}_{\mathrm{T}}$ 's for Various Fiber

Densities and Stopping Rules

\section{Flberg/Field}

0.1

0.2

0.5

1

1

2

5

6

$\geq 7$

\section{Flberg}

10

20

50

100

(100)

(100)

(100)

120

$\geq 140$
Flelds

(100)

(100)

(100)

(100)

100

50

20

(20)

(20)
F1g. 3

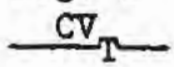

0.41

0.29

0.18

0.11

Not applicable

Not applicable

Not applicable

$$
0.10
$$

No data available

in this range 


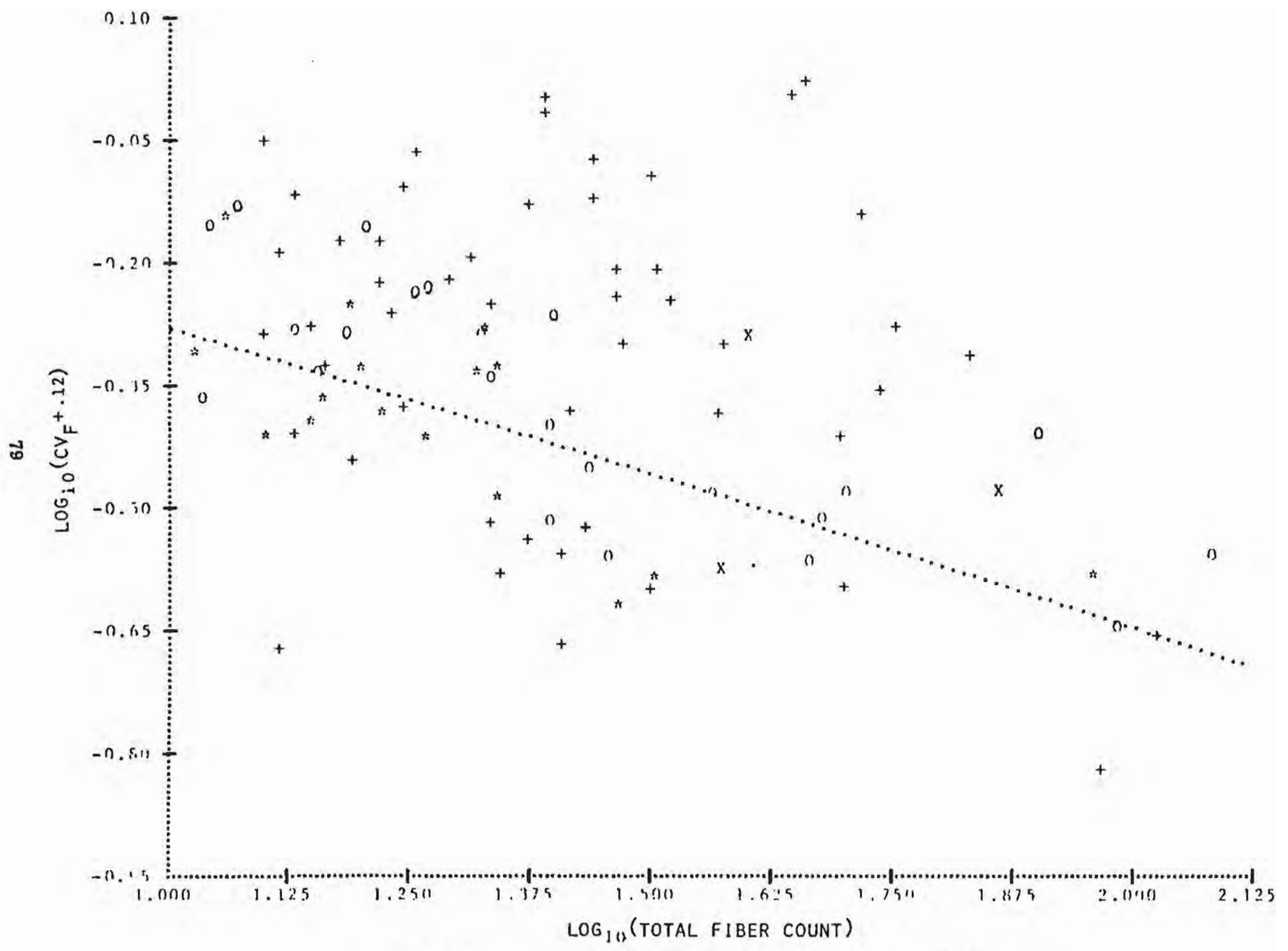

Pigare 1 - Variance-weighted regression curve for log

Jolms-Manville data (adjusted for bfas and willout pump error) 

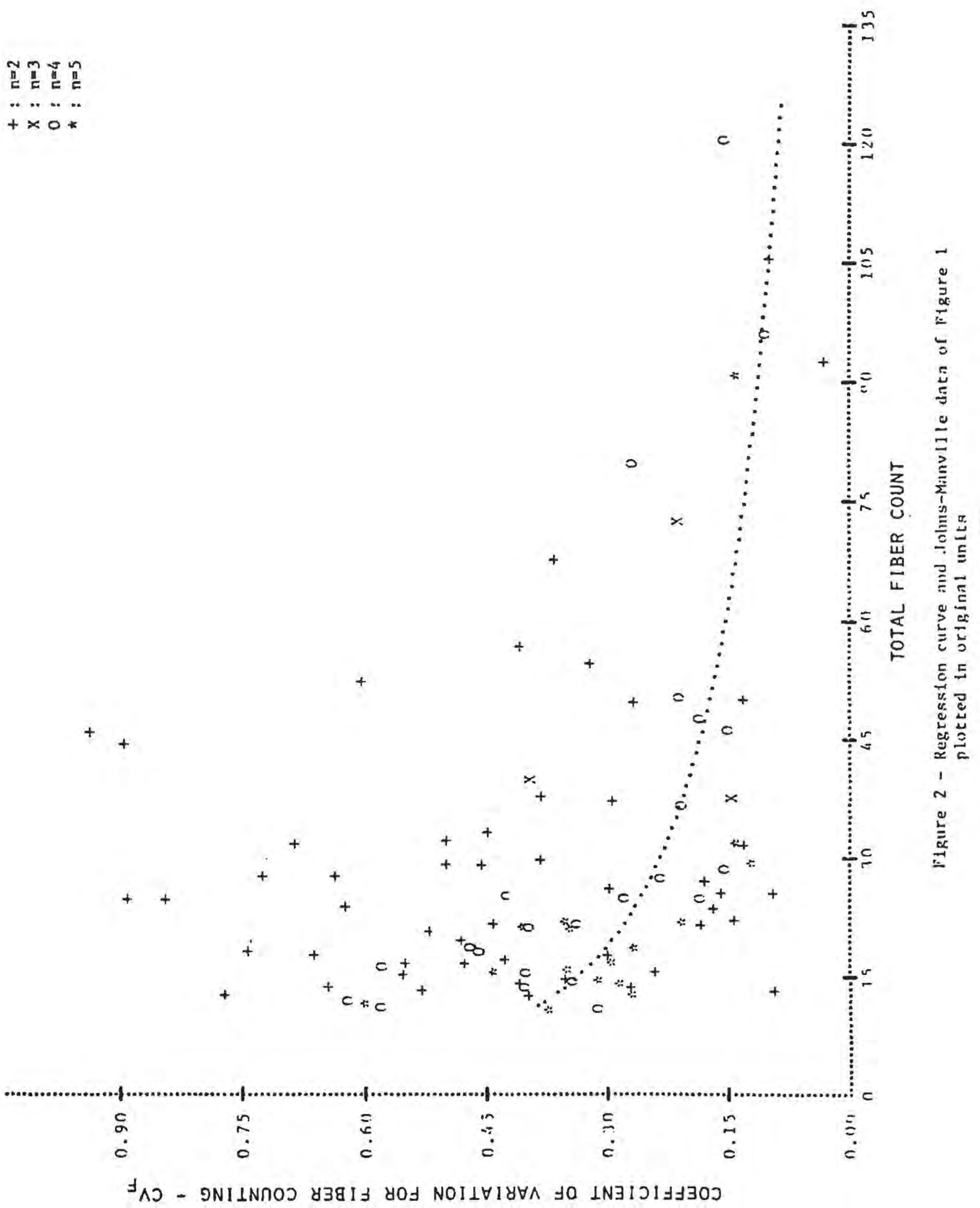


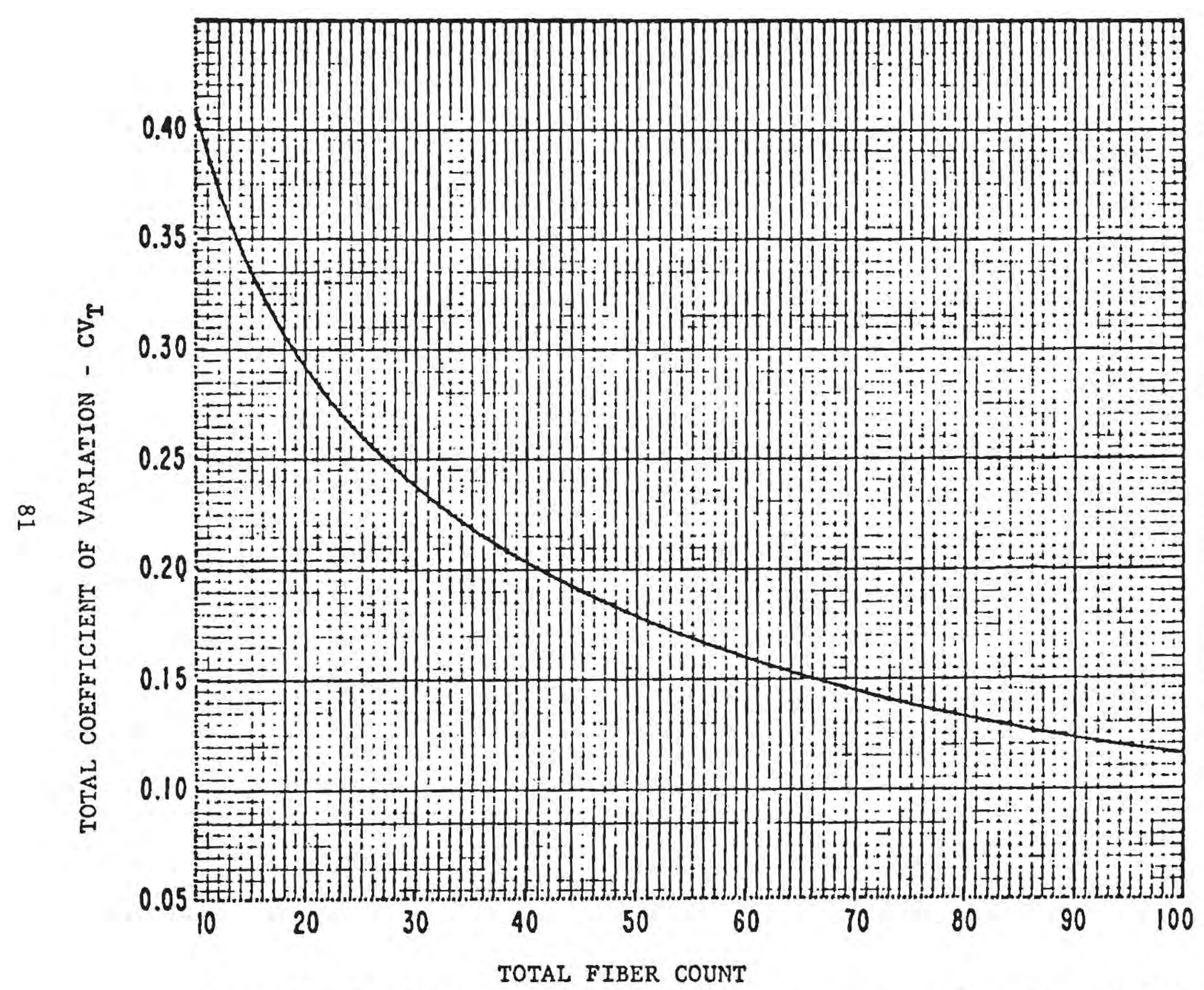

Figure 3 - Total coefficient of variation as a function of total fiber count (Including punp error) 


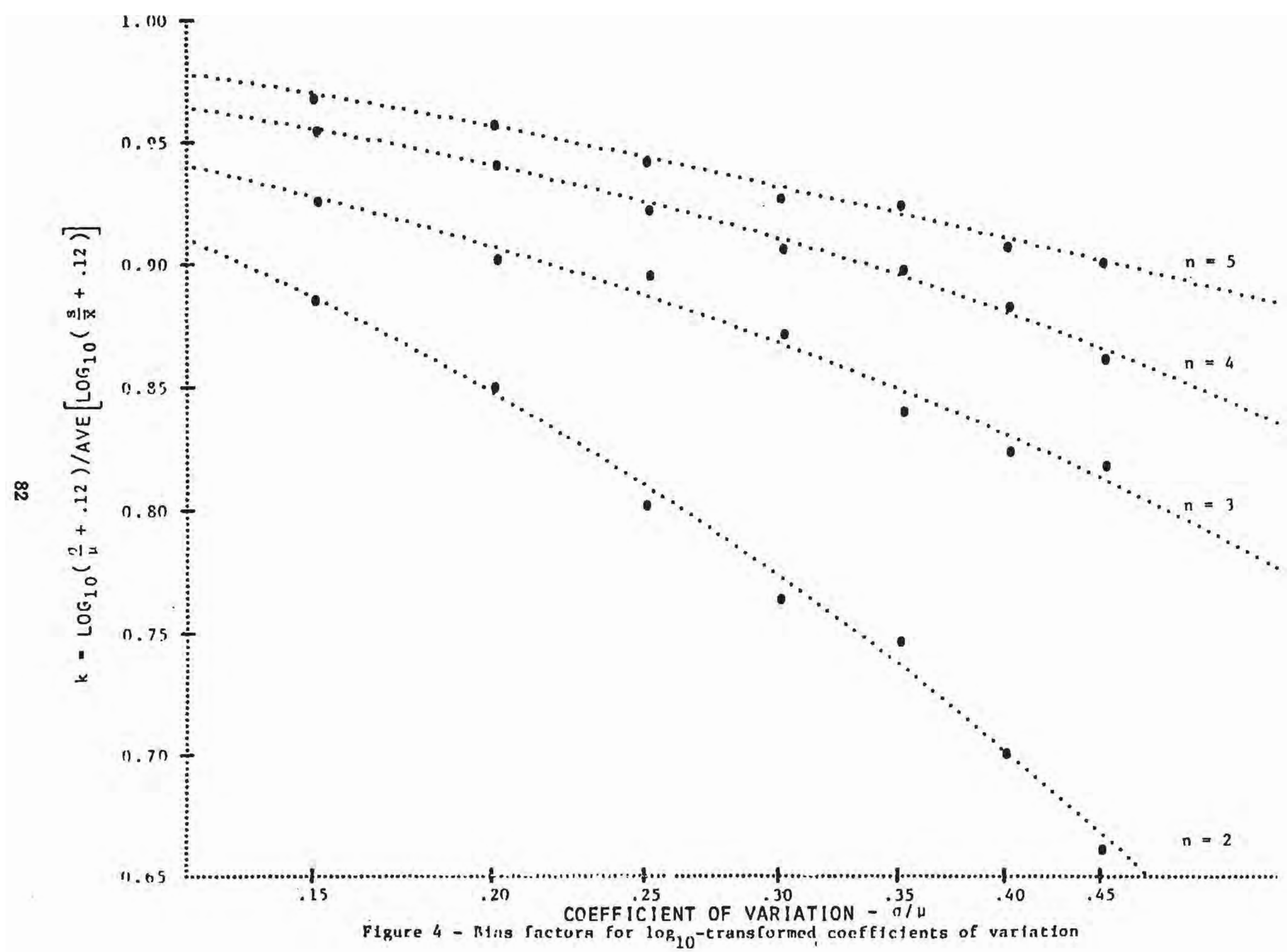




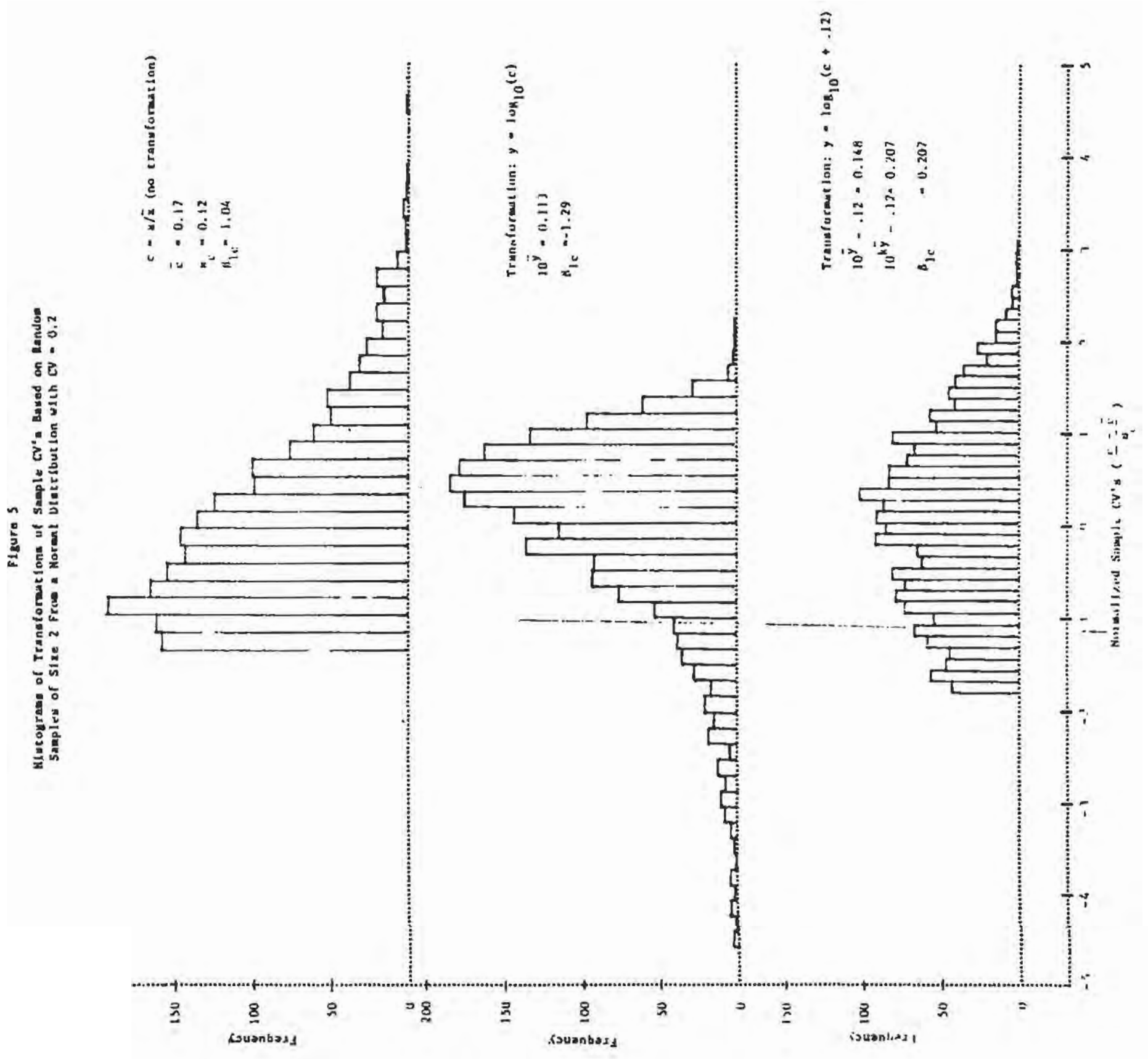




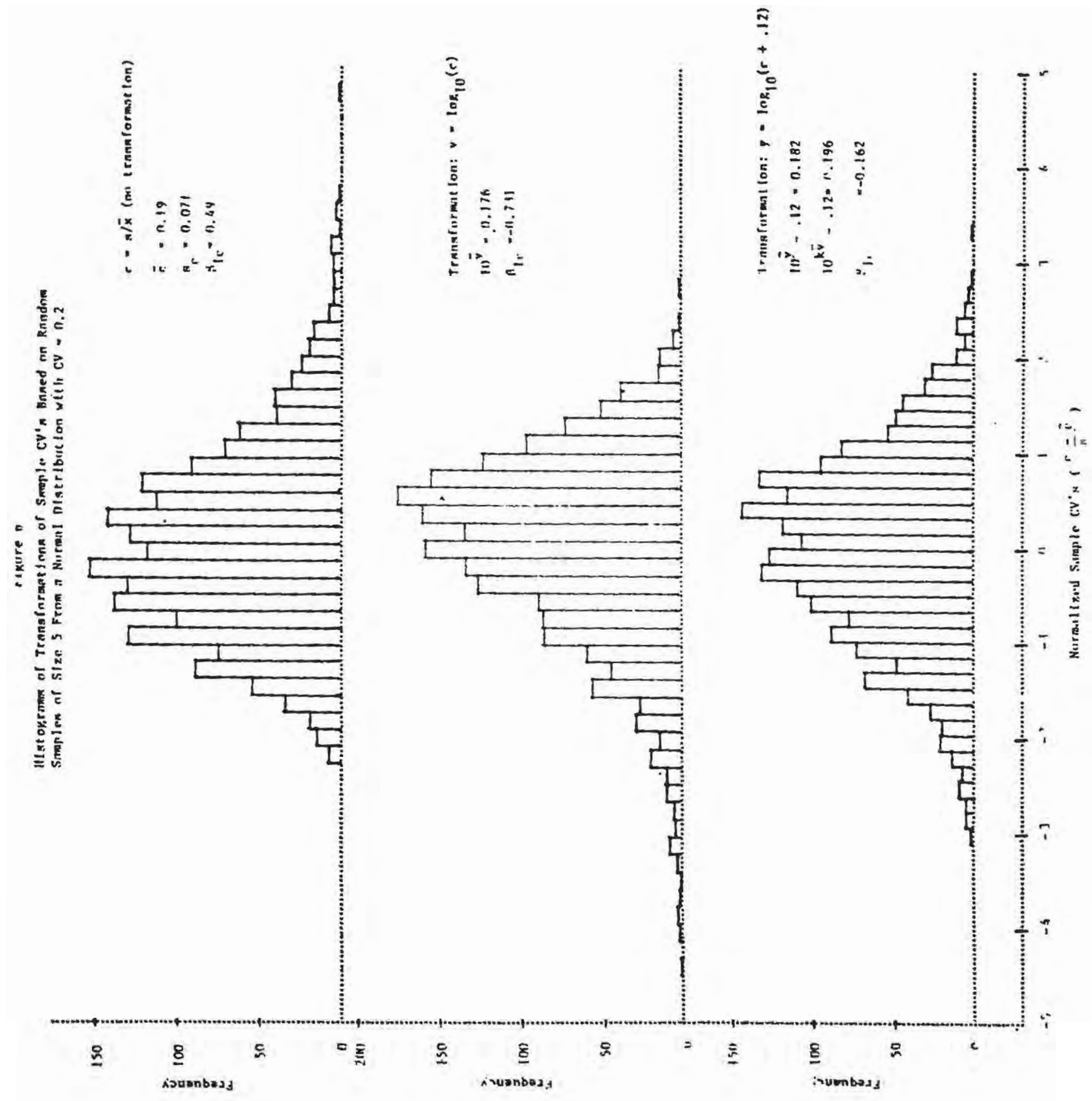




\section{$\$ 1910.1001$ Aobestos.}

(a) Definitions. For the purpose of this section. (1) "Asbestos" includes chrysotile, amosite. crocidolite, tremoUte, anthophyllite, and actinolite.

(2) "Asbesios fibers" means asbestos flbers longer than 5 micrometers.

(b) Permissible exposure to airborne concentrations of asbestos fibers-(1) Standard effective July 7, 1972. The 8-hour time-weighted average alrborne concentrations of asbestos fibers to which any employee may be exposed shall not exceed five flbers, longer than 5 micrometers, per cublc centimeter of air, as determined by the method prescribed in paragraph (e) of this section.

(2) Standard effective July 1, 1976. The 8-hour time-welghted average adrborne concentrations of asbestos fibers to whlch any employee may be exposed shall not exceed two fibers, longer than 5 micrometers, per cublc centimeter of air, es determined by the method prescribed in paragraph (e) of this sectlon.

(3) Ceiling concentration, No empioyee shall be exposed at any time to alrborne cencentrations of asbestos fibers in excess of 10 flbers, longer than 5 micrometers, per cublc centimeter of atr, as determined by the method prescribed in paragraph (e) of this section.

(c) Methods of compliance-(1) Engineering methods. (s) Engineering controls. Engineering controls, such as, but not limited to, Isolstion, enclosure, exhaust ventilation, and dust collection shall be used to meet the exposure limtts prescribed in paragraph (b) of thls section.

(1i) Local exhaust ventilation. (a) Local exhaust ventllation and dust collectlon systems shall be designed, constructed, Installed, and maintalned in accordance with the American National Standard Fundamentals Governing the Design and Operation of Local Exhaust Systems, ANSI Z9.2-1971, whlch is incorporated by reference hereln.

(3) See \& 1910.6 conceming the avallablilty of ANSI 29.2-1971, and the maintenance of a historlc fle in connection therewith. The address of the American National Standards Instltute is given in \& 1910.100.

(iii) Particular tools. All hand-operated and power-operated tools which may produce or release asbestos fibers in excess of the exposure limits pre- 
scrlbed in paragraph (b) of this section, such ns, but not limited to, saws, scorers, abraslve wheels, and drills, shall be provided with local exhaust ventliation systems in accordance with subdivision (II) of this subparagraph.

(2) Work practices-(I) Wet methods. Insofar as practicable, asbestos shall be handled. mixed, applied, removed, cut, scored, or otherwise worked in B wet state sufficient to prevent the emission of elrborne flbers in excess of the exposure IImIts prescribed in peragtaph (b) of this section, unless the usefulness of the product would be diminlshed thereby.

(Ii) Particular products and operations. No asbestos cement, mortar, coatInG, grout, plaster, or simllar material containing asbestos sholl be removed from bags, cartons, or other containers In which they are shipped, without being either wetted, or enclosed. or ventilated so as to prevent effectively the release of a.trborne asbestos nbers in excess of the limits prescribed in paragraph (b) of this sectlon.

(li1) Spraying, detnolttion, or removal. Employees engaged in the spraying of Rsbestos, the removal, or demolition of plpes, structures, or equipment covered or Insulated with asbestos, and in the remoral or demolition of asbestos insulation or coverings shall be provided with respiratory equipment in sccordance with paragraph (d) (2) (111) of this sectlon and with speclal clothing In sccordance with paragraph (d) (s) of this sectlon.

(d) Persona! protective equipment(1) Complinnce with the exposure limits prescrited by pa:agreph (b) of this sectinn may not bs echteved by the usc of resplrators or shift rotation of employces. except:

(i) Luring the time period necossary to finstall the engineering controls and to institute the work practices reouired by paragraph (c) of this scetion;

(i1) in work situations in which the methods prescrlbed in paragraph (c) of this section are elther technically not feasible or feasible to an extent Insiuffcient to reduce the alrborne concentratlons of asbestos fibers below the limits prescribed by paragraph (b) of this section: or

(iil) In cmergencles.

(iv) Wherc both respirators and nersonnel rotation are allowed by subdivi. slons (1), (11), or (iil) of this subparagraph, and both are practicable, personnel rotation shall be preferred and used.

(2) Where a respirator is permitted by subparagraph (1) of this paragraph. It shall be selected from among those approved by the Bureau of Mines, Department of the Interior, or the National In. stitute for Occupational Safety and Health, Department of Health. Education, and Welfare, under the provisions of 30 CFR Part 11 (37 F.R. 6244, Mar. 25, 1972), and shall be used in accordance with subdivisions (1), (ii), (iii), and (iv) ol this subparanraph.

(1) Air purifying respirators. A reusable or single use air purifying respirator. or a resplrator described in subdiviston (ii) or (iii) of this subparagraph, shall be used to reduce the concentrations of airborne asbestos flbers in the resplrator below the exposure limlts prescribed in paragraph (b) of this section. when the celling or the 8-hour time-weighted average airborne concentrations of asbestos fibsrs are reasonably expected to exceed no more than 10 times those limits.

(11) Powered air puri/ying respirators. A full faccplece powered alr purlfying respirator, or a powered alr purlfying respirator, or a respirator described in subdivision (iil) of this subparagraph. shall be used to reduce the concentrations of airborne asbestos flbers in the respirator below the exposure limits prescribed in paragraph (b) of this section, when the celling or the B-hour timeweighted average concentratlons of asbestos flbers ere reasonably expected to exceed 10 tlmes, but not 100 tlmes. those limits.

(1ii) Type "C" supplicd-air respirators continisous flow or pressure-demand ciass. A type "C" continuous flow or pressure-demand. supplied-air respirator shall be used to reduce the concentratlons of alrbome esbestos flbers in the respirator below the exposure limits prescribed In paragraph (b) of this section. when the ceiling or the B-hour timeweighted average alrborne concentra. tlons of asbestos flbers are reasonably expected to excec. 1100 times those limits.

(Iv) Establishment of a respirator program. (a) The employer shall establish a resplrator program in accordance with the requirements of the American $\mathrm{Na}$ tlonal Standards Practioos for Reenirn. tory Protection, ANSI Z88.2-1969, which is incorporated by reference herein. 


\section{$\$ 1910.1001$}

(b) See $\$ 1910.6$ concerntng the avallabllity of ANSI Z88.2-1969 and the matrtenance of an historic fle in connection therewlth. The address of the American National Standards Institute is glven in 1910.100 .

(c) No employee shall be assigned to tasks requiring the use of respirators if. based upon his most recent examination, an examining physlcian determines that the employee will be unable to function normally wearing a respirator, or that the safety or health of the employee or other employees will be Impaired by his use of a respirator. Such employee shall be rotated to another job or given the opportunity to transfer to a different position whose duties he Is ab?e to perform with the same employer, In the same geoEraphical area and with the same senlorIty, status, and rate of pay he had just prior to such transfer, if such a different position Is avallable.

(3) Special clothing: The employe shall provide, and require the use of, speclal clothing, such as coveralls or similar whole body clothing, head coverings, Bloves, and foot coverings for any employee exposed to airborne concentrations of asbestos fibers, which exceed the ceiling level prescribed in paragraph (b) of this section.

(4) Change rooms: (1) At any fixed place of employment exposed to airborne concentrations of asbestos fibers in excess of the exposure limits prescribed in paragraph (b) of this section, the employer shall provide change rooms for employees working regularly at the place

(ii) Clothes lockers: The employer shall provide two separate lockers or contamers for each employee, so separated or isolated as to prevent contamination if the employee's street clothes from hls work clothes.

(ili) Laundering: (a) Laundering of asbestos contaminated clothing shaul be done so as to prevent the release of alrborne asbestos fibers in excess of the exposure limits prescribed in paragraph (b) ff this section.

(b) Any employer who gives asbestos. contaminated clothing to another person for laundering shall inform such person of the requirement in (a) of this subdivision to effectively prevent the release of alrborne asbestos flbers in excess of the exposure limits prescribed in paragraph (b) of this section.

(c) Contaminated clothing shall be :ransported in sealed impermeable bags, or other closed, Impermeable contalners. and labeled in accordance with paragraph $(\mathrm{g})$ of this section.

(e) Method of measurcment. All determinations of alrborne concentrations of asbestos flbers shall be made by the membrane filter method at 400-450 $\times$ (magnification) (4 millimeter objective) with phase contrast llumination.

(f) Monitoring-(1) Initial determinations. Within 6 months of the publlcation of this section. every employer shall cause every place of employment where asbestos fibers are released to be monitored in such a way as to determine whether every employee's exposure to asbestos flbers is below the limits prescribed in paragraph (b) of this section. If the limits are exceeded, the employer shall immediately undertake a compliance program in accordance with paragraph (c) of thls section.

(2) Personal monitoring-(1) Samples shall be collected from within the breathing zone of the employees, on membrane filters of 0.8 micrometer porosity mounted in an open-face filter holder. Samples shall be taken for the determination of the 8-hour timeweighted average airborne concentrations and of the ceiling concentrations of asbestos fibers.

(ii) Sampling frequency and patterns. After the initial determinations required by subparagraph (1) of this paragraph, samples shall be of such frequency and pattern as to represent with reasonable accuracy the levels of exposure of employees. In no case shall the sampling be done at intervals greater than 6 months for employees whose exposure to asbestos may reasonably be foreseen to exceed the limits prescribed by paragraph (b) of this section.

(3) Environmental monitoring-(1) semples shell be collected from areas of a work environment which are representative of the airborne concentrations of asbestos fibers which may reach the breathing zone of employees. Samples shall be collected on 8 membrane filter of 0.8 micrometer porosity mounted in an open-face fllter holder. Samples shall be taken for the determination of the 8 hour time-weighted average airborne concentrations and of the ceiling concentrations of asbestos flbers.

(ii) Sampling frequency and patterns. After the initial determinations required by subparagraph (1) of this paragraph, samples shall be of such frequency and pattern as to represent with reasonable accuracy the levels of exposure of the 
employees, In no case shall sampling be at Intervals greater than 6 months for employees whose exposures to asbestos may reasonably be foreseen to exceed the exposure limlts prescribed in paragraph (b) of this section.

(4) Employee observation of monitoring. Affected employees. or thelr representatives, shall be glven a reasonable opportunity to observe any monitoring required by this paragraph and shall have access to the records thereof.

(g) Caution signs and labels. (1) Caution, signs. (1) Fosting. Caution slgns shall be provided and ilsplayed at each location where alrborne concentrations of asbestos fibers may be in excess of the exposure limits prescribed in paragraph (b) of this section. Slgns shall be posted at such a distance from such a location so that an employce may read the sions and take necessary protective steps before entering the area marked by the s!gns. Signs shall be posted at all approaches to areas containing excessive concentrations of airborne asbestos fibers.

(ii) Sign specifications. The tvarning signs required by subdivision (1) of this subparagraph shall conform to the requirements of $20^{\prime \prime} \times 14^{\prime \prime}$ vertical format signs specified In $\$ 1910.145(d)(4)$, and to this subdivision. The slgns shall display the following legend in the lower panel. with letter sizes and styles of a vislbility at leasi equal to that specificd in this subdlvision.

\begin{tabular}{|c|c|}
\hline Legend & Nciation \\
\hline wobestos ...... & $\begin{array}{l}\because \text { Sans Ser's, } \\
\text { Gothle or } \\
\text { Block. }\end{array}$ \\
\hline ust Fazard..... & $\begin{array}{l}\text { Sesns Berle. } \\
\text { Gothic or } \\
\text { Block. }\end{array}$ \\
\hline $\begin{array}{l}\text { Avold Breathleg Dust... } \\
\text { Wear Assigned :ratective } \\
\text { Equlpment. }\end{array}$ & $\begin{array}{l}1 / 1 \% \text { Gothlc. } \\
1 / 4 \text { Goth': }\end{array}$ \\
\hline $\begin{array}{l}\text { Do Nct Remrin In Area } \\
\text { Unless Your Work Re- } \\
\text { quires It. }\end{array}$ & : Cuth!c. \\
\hline $\begin{array}{l}\text { Bresthing Asbestco Dust } \\
\text { May Be Hezardous To } \\
\text { You- Hea:th. }\end{array}$ & 14 polat Go \\
\hline
\end{tabular}

spacing between lines shall be at icast equal to the helght of the upper of any two lines.

(2) Caution labels-(1) Labeling. Caution !abels sha!l be affixed to all raw materlals, mlxtures, scrap, waste, debris, and other products containing asbestos fbers, or to thelr containcrs, except that no label is required where osbestos fibers have been modified by a bondins agent. costlng, blnder, or other material so that during any reasonably foreseeable use, handling. storage, dlsposal, processing, or iransportation, no alrborne concentraUlons of asbestos flbers in excess of the exposure limits prescribed in paragraph (b) of this section will be released.

(i) Label specifications. The caution labels required by subdivision (1) of this subparagraph shall be printed in letters of sumcient size and contrast as to be readlly visible and legtblc. The label shall state:

$$
\text { C.ITTHON }
$$

Coata!ns Asbestos Flbers Avold Creating Dust

Breatiling Asbestos Dust May Cause Serious Bodlly Herm

(h) Iiousekeeping-(1) Cleaning. All external surfaces in any place of employmient shall be maintained free of Bccumulations of asiestos fibers if, with their dispersion, there would be an excessive concentration.

(2) Waste disposal. Asbestos waste, scrap, debris, bags, contalners, equlpment, and asbestos-contaminated clothlng. consigned for disposal, which may produce in any reasonably foreseeable use, handling, storage, processing, disposal, or transportation alrborne concentrations of asbestos flbers in excess of the exposure $1 \mathrm{~lm} 1 \mathrm{ts}$ prescribed in paragraph (b) of this section sliall be collected and alsposed of in sealed Impermeakle bags. o: other closed, Impermcable contalners.

(1) Recordkeeping-(2) Exposure records. Every employer shall maintain records of any personal or environmental monitoring required by this section. Records shall be maintained for a perlod of at least 3 years and shall be made avallsble upcn request to the Assistant Secretary of Labor for Gccupational Safety and Health, the Director of the Nations] Institute for Occupational Safety and Ifealth, and to atithorized representatives of either.

(2) Employec access, Every employee and former employee shali have reasonable access to any record required to be maintuined ty subparastrain (1) of this paragraph. which indicates the emplo'ee's own rxposure to nsbestos fluers.

(3) Employee rotification. Any employce found to have been exposed at any time to alrborne concentratlons of esbestos ribers in excess of the limits prescribed in paragraph (b) of this section shall be notified in writing of the exposure is soon as practicable but not later 
than 5 days of the finding. The employee shall also be timely notified of the corrective action belng taken.

(j) Medical examinations-(1) General. The employer shall provide or make available at his cost, medical examinations relative to exposure to asbestos required by this paragraph.

(2) Preplacement. The employer shal! provide or make available to each of his employees, within 30 calendar days following his first employment in an occupation exposed to : irborne concentrations of asbestos fibers, a comprehensive medical examination, which shall include, as a minimum, a chest roentgenograin (posterior-anterior $14 \times 17$ inches), a history to eliclt symptomatology of respiratory disease, and pulmonary function tests to include forced vital capacity (FVC) and forced expiratory volume at 1 second $\left(\mathrm{FEV}_{1,0}\right)$

(3) Annual examinations. On or before January 31,1973 , and at least annually thereafter, every employer shall provide, or make available, comprehensive medical examinations to each of his employees engaged in occupations exposed to altborne concentrations of asbestos flbers. Such annual examination sholl include, as a minimum, a chest roentgenogram (posterior-anterior $14 \mathrm{x}$ 17 inches), a history to ellclt symptomatology of resplratory disease, and pulmonary function tests to include forced vital capacity (FVC) and forced expiratory volume at 1 second $\left(\mathrm{FEV}_{1,0}\right)$

(4) Termination of employment. The employer shall provide, or make available, within 30 calendar days before or after the termination of employment of any employee engaged in an occupation exposed to airborne concentrations of asbestos fibers, a comprehensive medical examination which shall include, th a minimum, a chest roentgenogram (posterior-enterjor $14 \times 17$ inches), a nistory to eilcit symptomatelogy of resplratory ciseese, and pulmonary function tests is inclucie forced vital capacity (EVC) and forced expiratory volume at I second (FEV 10 ).

(5) Recent craminations. No medlcs] examination is required of any employee, if adequate records show that the employee has been examined in accordance wlth this paragraph within the past 1-year pcriod.

(6) Medical records-(1) Maintenance. Employers of employees examined pursuant to this paragraph shall cause wo be main'alned complete and accurate records of all such medical examina- tlons. Records shall be retalned by employers for at least 20 years.

(1i) Access. The contents of the records of the medical examinations required by this paragraph shall be made available, for inspection and copying, to the Assistant Secretary of Labor for Occupational Safety and Health, the Director of NIOSH, to authorized physiclans and medlcal consultants of elther of them, and, upon the request of an employee or former employee, to his physlcian. Any physician who conducts medical examination required by this paragraph shall furnlsh to the employer of the examined cmployee all the information specifically required by this paragraph, and any other medical information related to occupational exposure to asbestos fibers. 
DEPARTMENT OF

HEALTH, EDUCATION, AND WELFARE

PUBLIC HEALTH SERVICE

CENTER FOR DISEASE CONTROL

NATIONAL INSTITUTE FOR OCCUPATIONAL SAFETY AND HEALTH

ROBERT A TAFT LABJRATORIES

4676 COLUMGIA PARKWAY CINCINNATI. OHIO 43226

OFFICIAL BUSINESS

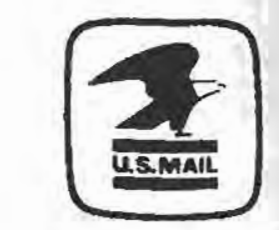

POSTAGE ANO KEEL PAIO

U DEFARTMENT OT N.E.W HEW 300

PENALTY FOR PRIVATE USE. \$300 